\title{
Midterm clinical outcomes with everolimus-eluting bioresorbable scaffolds versus everolimus-eluting metallic stents for percutaneous coronary interventions: a meta- analysis of randomised trials
}

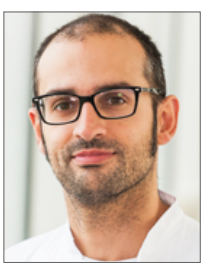

\author{
Salvatore Cassese $^{1 *}, \mathrm{MD}, \mathrm{PhD}$; Robert A. Byrne ${ }^{1}, \mathrm{MB}, \mathrm{BCh}, \mathrm{PhD}$; Peter Jüni², MD; \\ Joanna J. Wykrzykowska ${ }^{3}, \mathrm{MD}, \mathrm{PhD}$; Serban Puricel ${ }^{4}$, MD; Gjin Ndrepepa ${ }^{1}$, MD; \\ Heribert Schunkert ${ }^{1,5}$, MD; Massimiliano Fusaro ${ }^{1}$, MD; Stephane Cook ${ }^{4}$, MD; \\ Takeshi Kimura $^{6}$, MD; Jose P. S. Henriques ${ }^{3}$, MD; Patrick W. Serruys ${ }^{7}$, MD; \\ Stephan Windecker ${ }^{8}$, MD; Adnan Kastrati ${ }^{1,5}$, MD
}

1. Deutsches Herzzentrum München, Technische Universität München, Munich, Germany; 2. Applied Health Research Centre, Li Ka Shing Knowledge Institute of St. Michael's Hospital, and Department of Medicine, University of Toronto, Toronto, Canada; 3. AMC Heartcenter, Academic Medical Center, University of Amsterdam, Amsterdam, the Netherlands; 4. Department of Cardiology, University and Hospital Fribourg, Fribourg, Switzerland; 5. DZHK (German Centre for Cardiovascular Research), partner site Munich Heart Alliance, Munich, Germany; 6. Department of Cardiovascular Medicine, Kyoto University Hospital, Kyoto, Japan; 7. The National Heart and Lung Institute, Imperial College London, London, United Kingdom; 8. Department of Cardiology, Bern University Hospital, University of Bern, Bern, Switzerland

GUEST EDITOR: Fernando Alfonso, MD, PhD, FESC; Department of Cardiology, Hospital Universitario de La Princesa, Universidad Autónoma de Madrid, Madrid, Spain

This paper also includes supplementary data published online at: http://www.pcronline.com/eurointervention/128th_issue/252

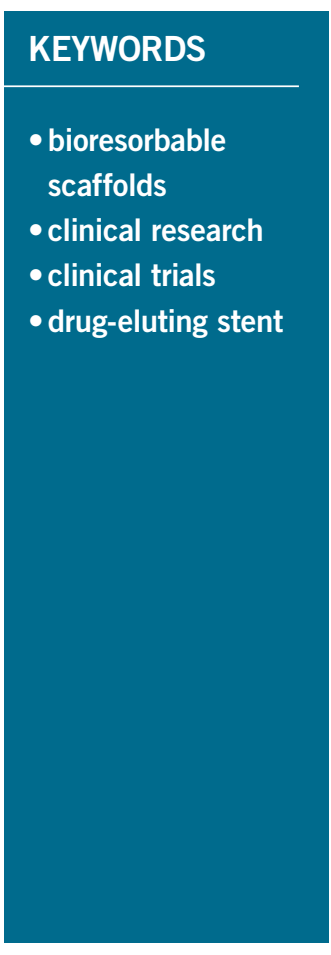

\begin{abstract}
Aims: The aim of this meta-analysis was to compare the midterm clinical outcomes of patients treated with an everolimus-eluting bioresorbable vascular scaffold (BVS) versus an everolimus-eluting metallic stent (EES) for percutaneous coronary interventions.
\end{abstract}

Methods and results: We performed a meta-analysis of aggregate data by searching Medline, EMBASE, Cochrane databases and proceedings of international meetings for randomised trials reporting the clinical outcomes beyond one year of patients treated with BVS versus EES. The primary efficacy and safety outcomes were target lesion failure (TLF) and definite/probable stent (scaffold) thrombosis (ST), respectively. Secondary outcomes were the individual components of the primary efficacy outcome (cardiac death, target vessel myocardial infarction [MI], and ischaemia-driven target lesion revascularisation [ID-TLR]). A total of 5,583 patients randomly received BVS $(n=3,261)$ or EES $(n=2,322)$ in seven trials. Weighted median follow-up was 26.6 months. Patients treated with BVS versus EES showed a higher risk of TLF (odds ratio [OR] 1.35, 95\% confidence interval [CI]: 1.11-1.65; $\mathrm{p}=0.0028)$ due to a higher risk of target vessel MI (OR 1.68, 95\% CI: 1.21-2.33; p=0.008) and ID-TLR (OR 1.42, 95\% CI: 1.10-1.84; $\mathrm{p}=0.007$ ) though the risk for cardiac death was not statistically different (OR 0.89, 95\% CI: 0.55-1.43; $\mathrm{p}=0.56$ ). Patients treated with BVS versus EES showed a higher risk of definite/probable ST (OR 3.24, 95\% CI: 1.92-5.49; p<0.0001), particularly in the period beyond one year after implantation (OR 4.03, 95\% CI: 1.49-10.87; $\mathrm{p}=0.006$ ).

Conclusions: At midterm follow-up, patients treated with BVS as compared to those treated with EES display a higher risk of target lesion failure and scaffold thrombosis.

\footnotetext{
*Corresponding author: Deutsches Herzzentrum München, Technische Universität München, Lazarettstrasse, 36,80636 Munich, Germany.E-mail: cassese@dhm.mhn.de
} 


\section{Abbreviations}

BVS bioresorbable vascular scaffold

EES everolimus-eluting stent

PCI percutaneous coronary intervention

ST stent thrombosis

TLF target lesion failure

TLR target lesion revascularisation

\section{Introduction}

The everolimus-eluting bioresorbable vascular scaffold (BVS) (Absorb ${ }^{\mathrm{TM}}$; Abbott Vascular, Santa Clara, CA, USA) is the only fully bioresorbable platform to have received approval for clinical use from regulatory agencies in both Europe and the USA ${ }^{1}$. Indeed, the BVS device has been evaluated in a number of randomised trials in patients with obstructive coronary artery disease with comparison against the widely used everolimus-eluting metallic stent (EES), showing broadly comparable clinical outcomes at 12 months after implantation ${ }^{2,3}$.

By providing only transient support of the dilated vessel, it has been hypothesised that bioresorbable scaffolds might improve long-term vessel healing and remodelling, restore vasomotor function of the treated segment, and potentially eliminate the accrual of late adverse events after percutaneous coronary intervention (PCI) in comparison with conventional drug-eluting stent (DES) platforms $\mathrm{s}^{4}$. Recently, however, a dedicated randomised trial failed to demonstrate either physiological or clinical advantages at three years with BVS as compared to $\mathrm{EES}^{5}$.

In the light of a number of trial reports investigating comparative efficacy beyond one year that have recently become available, we performed a meta-analysis of randomised trials to evaluate the efficacy and safety of BVS as compared to conventional metallic stents.

\section{Editorial, see page 1506}

\section{Methods}

\section{SEARCH STRATEGY AND SELECTION CRITERIA}

We searched Medline, EMBASE, the Cochrane Central Register of Controlled Trials (CENTRAL), scientific sessions abstracts and relevant websites (www.cardiosource.com, www.clinicaltrialresults.org, www.escardio.org, www.tctmd.com, www.theheart.org) for randomised trials comparing everolimus-eluting bioresorbable scaffolds versus conventional EES for PCI without restrictions concerning language or publication status. Inclusion criteria were: (1) randomised design, and (2) follow-up $>12$ months. Comparisons other than BVS versus EES were ineligible. We updated a previous search of scientific databases for articles dealing with the topic under investigation published or posted between November 2006 and October $2015^{3}$ up to May 2017. The reference lists from all eligible studies were checked to identify further citations.

\section{DATA COLLECTION AND ASSESSMENT OF RISK OF BIAS}

Two investigators (S. Cassese and R.A. Byrne) independently assessed publications for eligibility at title and/or abstract level. Divergences were resolved by consensus. Studies that met inclusion criteria were selected for further analysis. The same two investigators independently evaluated the risk of bias for each study in accordance with The Cochrane Collaboration method ${ }^{6}$. Composite quality scores were not assigned ${ }^{7}$.

\section{OUTCOMES}

For the current report, the primary efficacy outcome was target lesion failure (TLF), the device-oriented composite endpoint including cardiac death, target vessel myocardial infarction (MI), or ischaemia-driven target lesion revascularisation (ID-TLR); the primary safety outcome was definite/probable stent (scaffold) thrombosis (ST). Secondary outcomes were the individual components of the primary efficacy outcome. Other outcomes of interest were death, MI, TLR and any revascularisation. All endpoints were evaluated according to the intention-to-treat principle and the definitions reported in the original protocols.

\section{STATISTICAL ANALYSIS}

Odds ratios (ORs) with $95 \%$ confidence intervals (95\% CI) were used to compare outcomes of interest between BVS and EES and pooled using the Mantel-Haenszel fixed-effect model and the Hartung-Knapp random-effect model with or without the modification of the variance estimate, as appropriate ${ }^{8,9}$. For the primary efficacy and safety outcomes, we also derived the numbers needed to treat (or to harm) ${ }^{10}$ from random-effects pooled risk ratios and the risk observed in the control group of the Amsterdam Investigator-initiateD Absorb strategy (AIDA) all-comers trial ${ }^{11}$, which had a less selective patient inclusion than the other trials. All outcomes were primarily evaluated at the longest follow-up available. In addition, the ORs for primary outcomes and ID-TLR were calculated at 12-month and 24-month follow-up, and with landmark analyses beyond 12-month and 24-month follow-up. Heterogeneity between trials was quantified using the $\mathrm{I}^{2}$ statistic accompanied by a $\chi^{2}$ test: $\mathrm{I}^{2}$ values around $25 \%, 50 \%$ and $75 \%$ were suggested to indicate low, moderate or high heterogeneity, respectively ${ }^{12}$. In addition, we estimated the between-study variance $\left(\tau^{2}\right)$. The possibility of small study effects resulting from publication bias or other biases was examined for primary outcomes by means of visual inspection of funnel plots of the ORs of individual trials against their standard errors, accompanied by a statistical test of asymmetry ${ }^{13}$. An influence analysis, in which meta-analysis estimates are computed omitting one study at a time, was performed for primary outcomes. Using a $\chi^{2}$ test for subgroup by treatment interaction, we determined whether the type of sponsorship (industry- versus investigator-initiated) was associated with estimated ORs of primary outcomes. Finally, we determined the power of our random-effects meta-analysis to detect a pre-specified $25 \%$ relative risk reduction of TLF and a $50 \%$ relative risk reduction of definite/probable ST conditional on the observed precision of the pooled estimate ${ }^{14}$. This study was reported in compliance with the Preferred Reporting Items for Systematic reviews and Meta-Analyses (PRISMA) statement (Supplementary Table 1$)^{15}$. All analyses were performed in R, 
version 3.3.2 (R Foundation for Statistical Computing, Vienna, Austria) or with the use of the metareg command in Stata 13.1 (StataCorp, College Station, TX, USA).

\section{Results}

The electronic search identified seven randomised trials investigating BVS versus EES with follow-up data beyond one year: two trials reported as full-length manuscripts ${ }^{5,11}$ and five reported as meeting presentations ${ }^{16-20}$. These trials totalling 5,583 enrolled participants were included (Supplementary Figure 1).

The main characteristics of the included trials are described in detail in Supplementary Table 2. Briefly, PCI patients were randomised to a treatment with BVS $(n=3,261)$ or EES $(n=2,322)$. Individuals randomised to BVS were treated with the Absorb stent $^{21}$, while those randomised to EES were treated with cobaltchromium EES (XIENCE V ${ }^{\circledR}$, XIENCE Prime ${ }^{\circledR}$ or XIENCE Xpedition $^{\circledR}$; Abbott Vascular) $(n=2,242)$ or platinum-chromium EES (PROMUS Element ${ }^{\mathrm{TM}}$; Boston Scientific, Marlborough, MA, USA) $(n=80)^{16}$. Three out of seven trials included patients with acute $\mathrm{MI}^{11,16,17}$. In three trials ${ }^{5,16,18}$ the primary endpoint consisted of angiographic measures of efficacy, in one trial ${ }^{17}$ of imaging measures of efficacy, while the remaining trials were powered for composite clinical outcomes ${ }^{11,19,20}$. Two studies scheduled control angiography 36 months after index intervention ${ }^{5,20}$. One tria $1^{11}$ had descriptive outcomes data made available after a median followup duration of 24 months, which was included in our analyses.

The definitions used for outcomes are described in detail in Supplementary Table 3. All interventions were performed in accordance with standard of care, including stent deployment optimisation or use of intravascular imaging techniques, at the operators' discretion or according to protocols. Overall, predilation was performed in 3,556 (97.6\%) of 3,640 lesions treated with BVS and in 2,496 (93.2\%) of 2,676 lesions treated with EES; postdilation was performed in $2,471(67.7 \%)$ of 3,646 lesions treated with BVS and 1,459 (54.3\%) of 2,683 lesions treated with EES. Across included trials, the reported percentages of device success in the BVS group ranged between $92 \%$ and $99 \%$, while the percentages of procedural success ranged between $90 \%$ and $97 \%$. Anticoagulation during PCI was accomplished through administration of either unfractionated heparin or bivalirudin in all cases. After coronary interventions, aspirin was recommended indefinitely, whilst thienopyridines were prescribed for a period ranging from $\geq 6$ to 12 months. In six trials ${ }^{5,11,16,18-20}$, a proportion of patients ranging between $17.5 \%$ and $41.7 \%$ in the BVS group and between $14.0 \%$ and $38.1 \%$ in the EES group were actually on dual antiplatelet therapy (DAPT) at the time of last available followup. At 12 months, 2,840 (92.3\%) of 3,076 patients treated with BVS and 1,977 (91.4\%) of 2,161 patients treated with EES were actually on DAPT. At 24 months, 1,343 (49.1\%) of 2,732 patients treated with BVS and 791 (44.0\%) of 1,795 patients treated with EES were actually on DAPT. All study subjects received standard medical therapies as required. The evaluation of risk of bias among studies is reported in Supplementary Table 4.
The main characteristics of patients and lesions treated in the original trials are listed in Table 1. Individuals enrolled were more often male, with a median age of 63.5 years (interquartile range, 58.6-65.0), and about a quarter were diabetics. Approximately one third of cases presented with ACS at the time of index PCI. At baseline angiography, treated lesions displayed a mean diameter stenosis of $70.7 \%$, a reference vessel diameter of $2.70 \mathrm{~mm}$ and a length of $14.3 \mathrm{~mm}$. Two thirds of lesions treated had a complex morphology.

\section{OUTCOMES}

Among those randomised, 5,452 patients (97.6\%) were available for assessment of outcomes of interest. The weighted median follow-up was 26.6 months, ranging between 24 and 36 months.

\section{PRIMARY OUTCOMES}

Forest plots for primary outcomes are displayed in Figure 1. The primary efficacy outcome of TLF occurred in 496 patients (9.1\%). Patients treated with BVS versus EES showed a higher risk for TLF (10.1\% versus 7.6\%; OR 1.35 [1.11-1.65], $\mathrm{p}=0.0028$; $\left.\mathrm{I}^{2}=0 \%\right)$. The risk for TLF with BVS versus EES tended to increase at 12 months $(6.4 \%$ versus $5.2 \%$; OR 1.23 [0.97-1.56], $\mathrm{p}=0.08$, $\mathrm{I}^{2}=0 \%$ ) (Figure 2, Supplementary Figure 2A) and was significantly higher at 24 months $(9.5 \%$ versus $7.4 \%$; OR 1.32 [1.081.61], $\mathrm{p}=0.007, \mathrm{I}^{2}=0 \%$ ) (Figure 2, Supplementary Figure 2B). In the period beyond 12 months after implantation, TLF occurred in 115 patients treated with BVS and in 53 patients treated with EES (3.6\% versus 2.3\%; OR 1.62 [0.96-2.73]; $\mathrm{p}=0.06, \mathrm{I}^{2}=19.9 \%$ ) (Supplementary Figure 2C). In the period beyond 24 months after implantation, TLF occurred in 18 patients treated with BVS and six patients treated with EES $(0.8 \%$ versus $0.5 \%$; OR 1.47 [0.514.20 ]; $\mathrm{p}=0.33, \mathrm{I}^{2}=0 \%$, data available for 3,316 patients). The number needed to harm to cause one case of TLF with the use of BVS up to an average follow-up of 26.6 months was 38 patients (20121). The random-effects meta-analysis had an $81 \%$ power to detect a $25 \%$ relative risk reduction of TLF associated with BVS.

The primary safety outcome of definite/probable ST occurred in 94 patients (1.7\%). Patients treated with BVS versus EES showed a higher risk for definite/probable ST (2.4\% versus $0.7 \%$; OR 3.24 [1.92-5.49], $\mathrm{p}<0.0001 ; \mathrm{I}^{2}=0 \%$ ). The risk for definite/probable ST with BVS versus EES was increased both at 12-month $(1.6 \%$ versus $0.6 \%$; OR 2.52 [1.41-4.49], $\mathrm{p}=0.0018, \mathrm{I}^{2}=0 \%$ ) (Figure 2, Supplementary Figure $3 \mathrm{~A})$ and at 24-month follow-up $(2.3 \%$ versus $0.7 \%$; OR 3.15 [1.86-5.34], $\mathrm{p}<0.001, \mathrm{I}^{2}=0 \%$ ) (Figure 2, Supplementary Figure 3B). In the period beyond 12 months after implantation, definite/probable ST occurred in 30 patients treated with BVS and in three patients treated with EES $(0.8 \%$ versus $0.1 \%$; OR 4.03 [1.49-10.87]; $\mathrm{p}=0.006, \mathrm{I}^{2}=0 \%$ ) (Supplementary Figure 3 C). In the period beyond 24 months after implantation, definite/probable ST occurred in two patients treated with BVS and in no patient treated with EES (OR 1.49 [0.15-14.39]; $p=0.73$, $\mathrm{I}^{2}=0 \%$, data available for 3,296 patients).

The number needed to harm to cause one case of definite/ probable ST with the use of BVS up to an average follow-up 
Table 1. Main baseline characteristics of patients and lesions randomised to BVS or EES among trials included in the study.

\begin{tabular}{|c|c|c|c|c|c|c|c|}
\hline & ABSORB China & ABSORB II & ABSORB III & ABSORB Japan & AIDA & EVERBIO II & TROFI II \\
\hline \multicolumn{8}{|l|}{ Patients } \\
\hline Randomised & 480 & 501 & 2,008 & 400 & 1,845 & 158 & 191 \\
\hline Age, years & $57.4(10.5)$ & $61.3(10.0)$ & $63.5(10.5)$ & $67.2(9.4)$ & $64.2(10.5)$ & $65.0(11.0)$ & $58.6(10.1)$ \\
\hline Male gender & $343 / 475$ (72.2) & $385(76.8)$ & $1,415 / 2,006(70.5)$ & $309(77.3)$ & 1,370 (74.2) & $125(79.1)$ & $157(82.1)$ \\
\hline Diabetes & $115 / 475(24.2)$ & $120(24.0)$ & $640 / 2,006$ (31.9) & $144(36.0)$ & $324(17.5)$ & $30(18.9)$ & $32(16.7)$ \\
\hline ACS at admission & $306 / 475(64.4)^{*}$ & $105(21.0)^{*}$ & $523 / 2,007(26.1)^{*}$ & $48(12.0)^{*}$ & $999(54.1)$ & $55(34.8)$ & $191(100)$ \\
\hline \multicolumn{8}{|l|}{ Lesions } \\
\hline Randomised & 503 & 546 & 2,098 & 412 & 2,446 & 208 & 193 \\
\hline Diameter stenosis, \% & $64.9(12.8)$ & 59.0 (11.2) & $65.5(12.2)$ & $64.6(11.0)$ & $N / R$ & $80.5(15.7)$ & 89.7 (15.2) \\
\hline RVD, mm & $2.82(0.44)$ & $2.60(0.39)$ & $2.66(0.46)$ & $2.74(0.45)$ & $2.67(0.47)$ & $2.58(0.65)$ & $2.81(0.49)$ \\
\hline Length, mm & $14.0(4.93)$ & $13.8(6.54)$ & $12.8(5.6)$ & $13.4(5.4)$ & $18.9(9.2)$ & $\mathrm{N} / \mathrm{R}$ & $13.1(7.2)$ \\
\hline Type B2/C & $369 / 502(73.5)$ & $254 / 543(46.8)$ & $1,462 / 2,089(70.0)$ & $313(76.0)$ & $1,288 / 2,439(52.8)$ & 67 (32.2) & 192/192 (100) \\
\hline \multicolumn{8}{|l|}{ Predilation } \\
\hline BVS & 250/251 (99.6) & $364 / 364(100)$ & $1,322 / 1,322(100)$ & $275 / 275(100)$ & 1,199/1,237 (96.9) & 93/96 (96.8) & $53 / 95(55.8)$ \\
\hline EES & $247 / 252(98.0)$ & $180 / 182(99.0)$ & $686 / 686(100)$ & 137/137 (100) & $1,103 / 1,209(91.2)$ & 96/112 (85.7) & $50 / 98(51.0)$ \\
\hline \multicolumn{8}{|l|}{ Post-dilation } \\
\hline BVS & $162 / 257(63.0)$ & $221 / 364(60.7)$ & $866 / 1,322(65.5)$ & $226 / 275(82.2)$ & $915 / 1,237(73.9)$ & $33 / 96(34.3)$ & $48 / 95$ (50.5) \\
\hline EES & $141 / 259(54.4)$ & $107 / 182(58.7)$ & $351 / 686$ (51.2) & 106/137 (77.4) & $594 / 1,209(49.1)$ & $35 / 112(31.2)$ & $25 / 98(25.5)$ \\
\hline \multicolumn{8}{|c|}{ 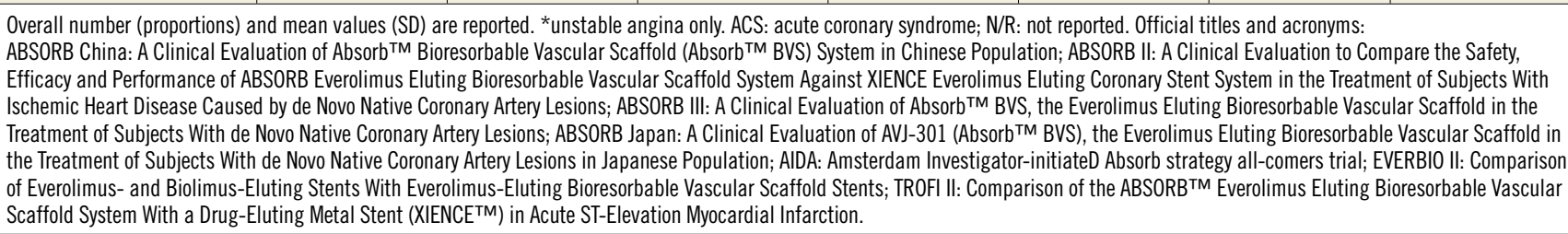 } \\
\hline
\end{tabular}

\section{A Target lesion failure}

\begin{tabular}{lrrrr} 
Trial & \multicolumn{2}{c}{ BVS } & \multicolumn{2}{c}{ EES } \\
& Events & Total & Events & Total \\
ABSORB China & 13 & 236 & 11 & 235 \\
ABSORB II & 34 & 325 & 8 & 161 \\
ABSORB III & 143 & 1,296 & 53 & 671 \\
ABSORB Japan & 23 & 258 & 7 & 128 \\
AIDA & 91 & 899 & 78 & 894 \\
EVERBIO II & 16 & 78 & 13 & 80 \\
TROFI II & 3 & 95 & 3 & 96 \\
Fixed effect model & $\mathbf{3 2 3}$ & $\mathbf{3 , 1 8 7}$ & $\mathbf{1 7 3}$ & $\mathbf{2 , 2 6 5}$ \\
Random effects model & & & &
\end{tabular}

Heterogeneity: $I^{2}=0 \%, \tau^{2}=0, p=0.82$

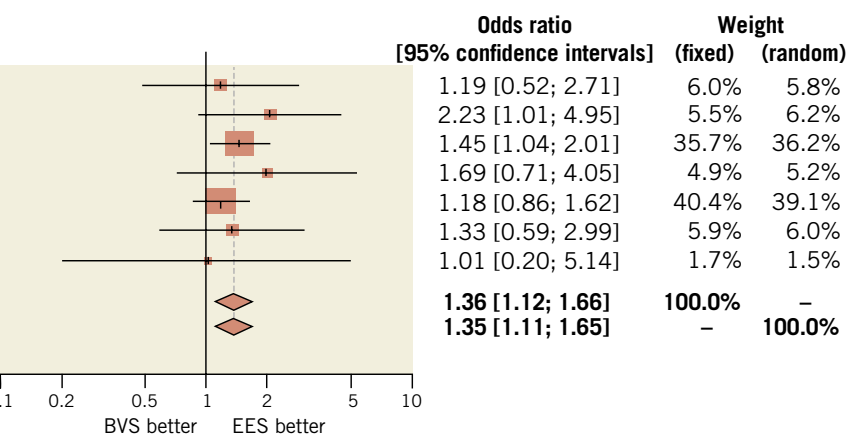

\section{B Definite or probable stent/scaffold thrombosis}

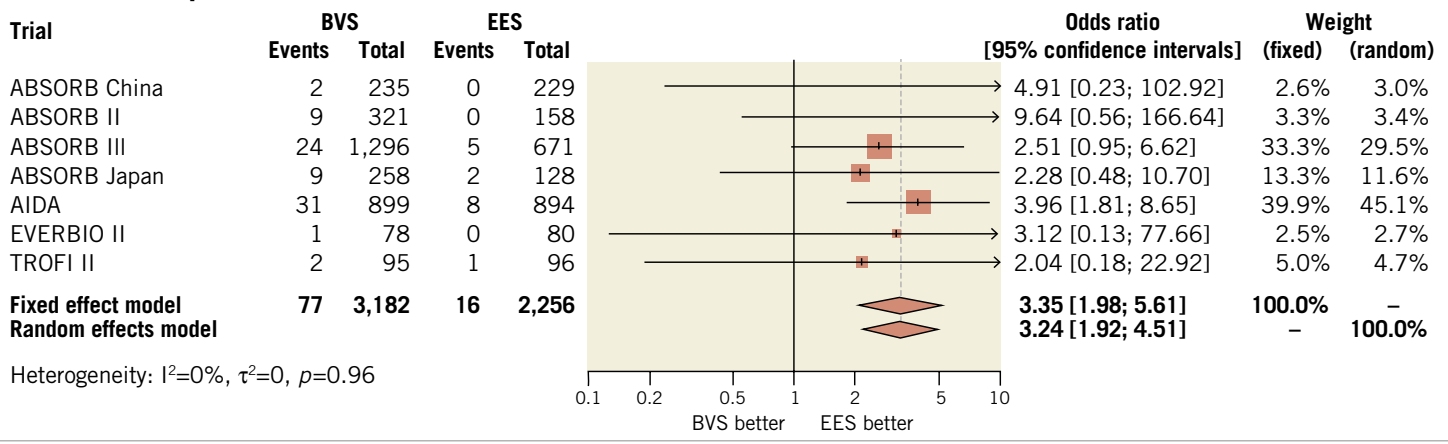

Figure 1. Forest plots for primary efficacy and safety outcomes with BVS versus EES. Odds ratios for target lesion failure (A) and definite/ probable stent (scaffold) thrombosis (B) with BVS versus EES. The diamonds indicate the point estimates and the left and the right ends of the lines the 95\% confidence intervals. BVS: bioresorbable scaffold; EES: everolimus-eluting stent 


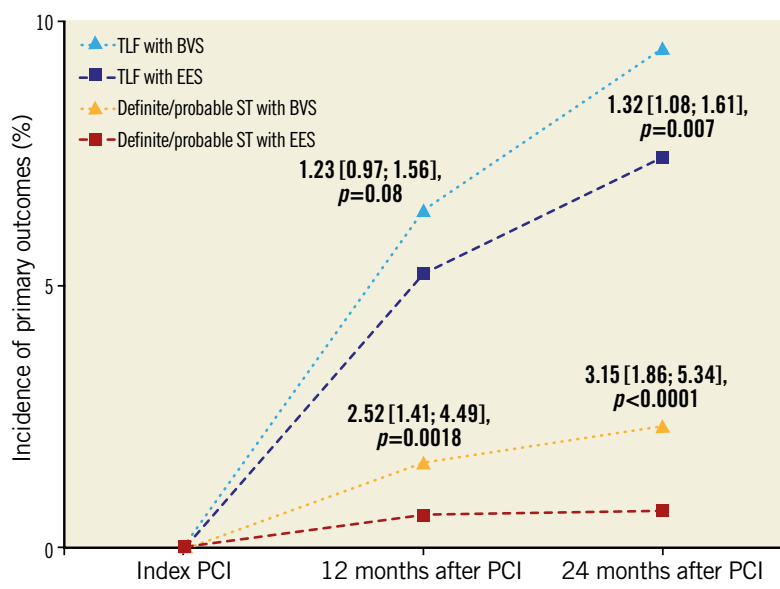

Figure 2. Incidences and odds ratios for primary outcomes at 12- and 24-month follow-up with BVS versus EES. The odds ratios for target lesion failure and definite or probable stent (scaffold) thrombosis 12 months and 24 months after PCI with BVS versus EES are presented with 95\% confidence intervals. BVS: bioresorbable scaffold; EES: everolimus-eluting stent; PCI: percutaneous coronary intervention; ST: stent (scaffold) thrombosis; TLF: target lesion failure

of 26.6 months was 63 patients (31-155). The random-effects meta-analysis had $73 \%$ power to detect a $50 \%$ relative risk reduction of definite/probable ST associated with BVS.

Definite ST occurred in 82 patients (1.5\%) and those treated with BVS versus EES showed a higher risk of definite ST $(2.2 \%$ versus $0.5 \%$; OR 3.64 [2.01-6.57], $\mathrm{p}<0.0001, \mathrm{I}^{2}=0 \%$ ) (Supplementary Figure 4A). Very late definite ST occurred in 27 patients treated with BVS and two patients treated with EES (1.0\% versus $0.08 \%$; OR 4.68 [1.55-14.13]; $\mathrm{p}=0.006, \mathrm{I}^{2}=0 \%$ ) (Supplementary Figure 4B).

\section{SECONDARY OUTCOMES}

Forest plots for secondary outcomes are displayed in Figure 3A-Figure 3C. Cardiac death occurred in 73 patients $(1.3 \%)$. The risk for cardiac death was not statistically different between patients treated with BVS and those treated with EES (1.2\% versus 1.5\%; OR 0.89 [0.55-1.43], $\mathrm{p}=0.56 ; \mathrm{I}^{2}=0 \%$ ).

Target vessel MI occurred in 264 patients $(4.8 \%)$ and those treated with BVS versus EES showed a higher risk for MI related to the target vessel (5.9\% versus 3.3\%; OR 1.68 [1.21-2.33], $\mathrm{p}=0.008 ; \mathrm{I}^{2}=0 \%$ ). Notably, the higher risk for target vessel MI of individuals treated with BVS versus EES persisted even after the exclusion of those events which occurred in the periprocedural phase $\left(3.4 \%\right.$ versus $1.8 \%$; OR 1.83 [1.05-3.17], $\mathrm{p}=0.037 ; \mathrm{I}^{2}=0 \%$, data available for 3,489 patients).

ID-TLR occurred in 284 patients (5.2\%). Patients treated with BVS versus EES showed a higher risk for ID-TLR (5.9\% versus $4.2 \%$; OR 1.42 [1.10-1.84], $\mathrm{p}=0.007 ; \mathrm{I}^{2}=0 \%$ ). The risk for ID-TLR with BVS versus EES tended to increase at 12 months (3.4\% versus $3.0 \%$; OR 1.20 [0.88-1.64], $\mathrm{p}=0.24, \mathrm{I}^{2}=0 \%$ ) and was significantly higher at 24 months $(5.2 \%$ versus $3.9 \%$; OR 1.41 [1.08-1.84], $\mathrm{p}=0.011, \mathrm{I}^{2}=0 \%$ ). In the period beyond 12 months after implantation, ID-TLR occurred in 74 patients treated with BVS and 21 patients treated with EES (2.3\% versus $0.9 \%$; OR 2.44 [1.50-3.97]; $\left.\mathrm{p}=0.0003, \mathrm{I}^{2}=40 \%\right)$. In the period beyond 24 months after implantation, ID-TLR occurred in 27 patients treated with BVS and six patients treated with EES (OR 2.97 [1.24-7.12]; $\mathrm{p}=0.007, \mathrm{I}^{2}=0 \%$, data available for 3,324 patients).

\section{OTHER OUTCOMES OF INTEREST}

Forest plots for other outcomes of interest are displayed in Supplementary Figure 5A-Supplementary Figure 5D. Patients treated with BVS versus EES showed a higher risk of MI $(7.3 \%$ versus 4.4\%; OR 1.59 [1.24-2.03], $\left.\mathrm{p}=0.0002 ; \mathrm{I}^{2}=0 \%\right)$ and TLR (5.9\% versus 4.8\%; OR 1.28 [1.00-1.64], $\mathrm{p}=0.046 ; \mathrm{I}^{2}=0 \%$ ), though the risk for any revascularisation $(13.5 \%$ versus $12.1 \%$; OR 1.11 [0.89-1.39], $\left.\mathrm{p}=0.28 ; \mathrm{I}^{2}=8 \%\right)$ and death $(2.3 \%$ versus $3.2 \%$; OR $0.76[0.54-1.07], \mathrm{p}=0.11 ; \mathrm{I}^{2}=0 \%$ ) was not statistically different.

\section{SMALL STUDY EFFECTS, INFLUENCE, SENSITIVITY AND SUBGROUP ANALYSES}

Funnel plots for TLF and definite/probable ST are presented in Supplementary Figure 6A and Supplementary Figure 7A. We found no evidence for small study effects, either by visual inspection of funnel plots or by asymmetry test. The influence analysis demonstrated that no single study significantly altered the direction of the summary ORs for TLF and definite/probable ST, respectively (Supplementary Figure 6B, Supplementary Figure 7B). The type of sponsorship for each included trial did not influence the risk estimates for primary outcomes.

\section{Discussion}

This meta-analysis of aggregate data investigates the clinical outcomes beyond one year of PCI patients randomised to a percutaneous revascularisation with either BVS or EES. At a median study-level follow-up of 26.6 months, BVS in comparison to EES showed: (i) lower efficacy due to a higher risk of TLF, and (ii) inferior safety due to a higher risk of ST, particularly in the period beyond 12 months after implantation.

BVS provide transient scaffolding of the target lesion during the initial months and years after implantation and then degrade into predominantly inert breakdown products after about three years ${ }^{2}$. Previously, a number of meta-analyses including data from trials enrolling patients with moderate lesion complexity and with follow-up up to one year found BVS associated with an overall clinical efficacy comparable to that of EES although a higher risk of ST was observed, particularly in the first 30 days after implantation $^{3,22}$. These findings are in broad agreement with those from registries including patients with somewhat more complex disease patterns $^{23}$. In response to these observations, it has been suggested that improved patient selection in conjunction with introduction of dedicated interventional protocols specific to BVS might result in improved performance of current-generation devices ${ }^{24}$. More recently, however, the first randomised trial comparing BVS and EES in relatively straightforward lesion morphologies has reported a higher risk of failure associated with the bioresorbable scaffolds 


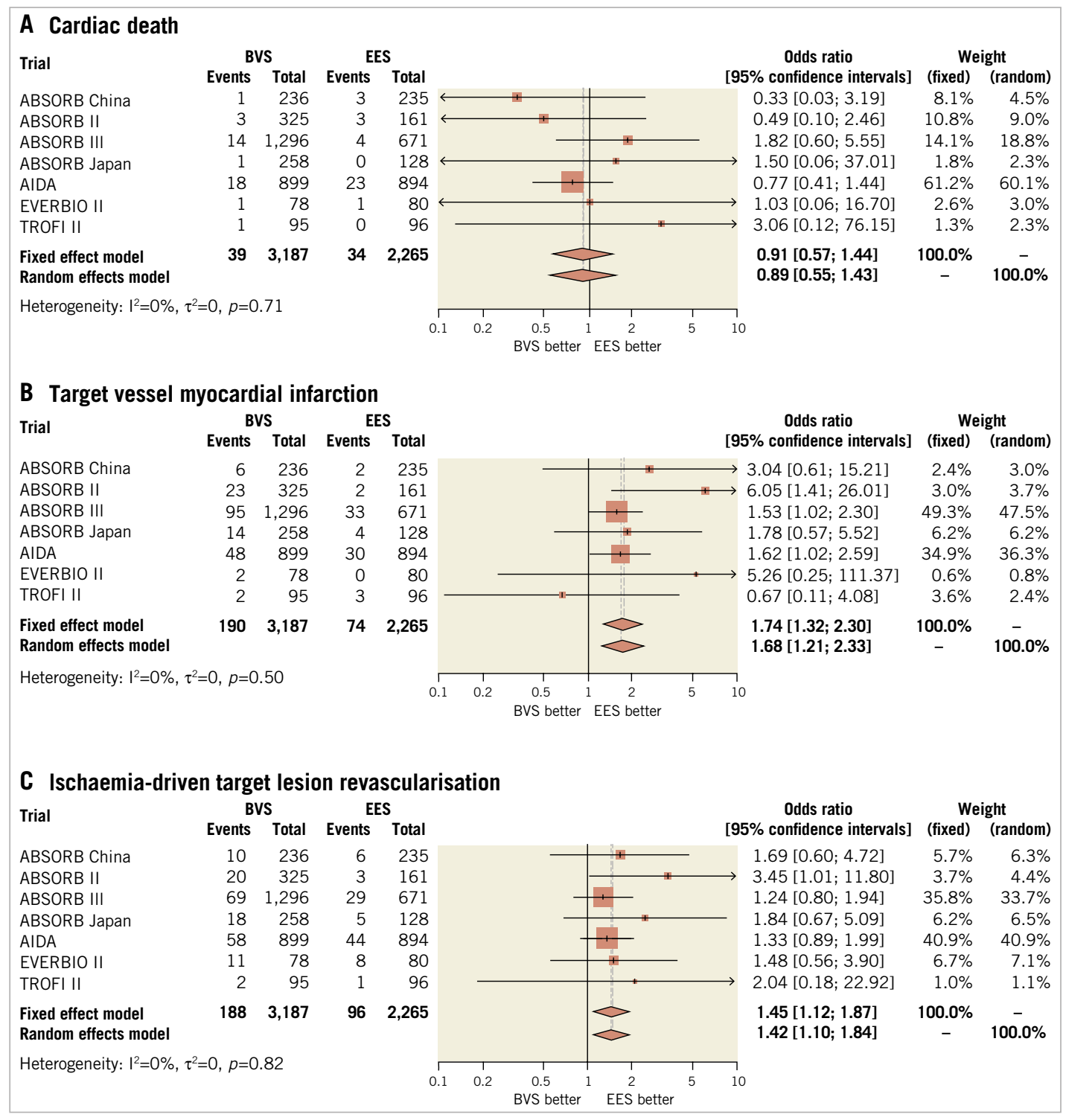

Figure 3. Forest plots of individual components of primary efficacy outcome with BVS versus EES. Odds ratios for cardiac death (A), target vessel myocardial infarction (B), and ischaemia-driven target lesion revascularisation (C) with BVS versus EES. The diamonds indicate the point estimates and the left and the right ends of the lines the 95\% confidence intervals. BVS: bioresorbable scaffold; EES: everolimus-eluting stent

up to three-year follow-up ${ }^{5}$. Notably, at this time point the antirestenotic drug should be completely eluted and the resorption process of BVS nearly completed ${ }^{21}$

In a study-level meta-analysis including three randomised trials and 21 observational studies ${ }^{25}$, Toyota and colleagues found a higher risk for definite/probable ST and a similar risk for TLF, 16.2 months after the percutaneous implantation of BVS as compared to EES. Similarly, in a recent meta-analysis of aggregate data from seven randomised trials, a PCI with BVS versus EES increased the risk for TLF and definite/probable ST at 24 months ${ }^{26}$.

To shed more light on the performance beyond one year of BVS as compared to EES, we analysed the totality of study-level data from seven randomised trials investigating this issue. The novelty of the present study is twofold: first, we studied efficacy and safety of BVS versus EES at the longest follow-up interval, since three out of seven trials included ${ }^{5,18,20}$ had three-year data available for this analysis. Second, the comparable follow-up periods accumulated among included trials allowed further insight into the time-dependent performance of BVS versus EES: indeed, the risk estimations for several outcomes were calculated not only at the longest follow-up but also at specific time points (12 and 24 months) and with two landmark analyses (beyond 12 and 24 months). These are the main differences from previous studies, which analysed efficacy and safety of BVS versus EES within wide ranges of follow-up intervals ${ }^{26}$.

In the present study, at a median follow-up of 26.6 months after index intervention, we found that the use of BVS as compared with EES increased the risk of TLF with a number needed to harm of 38. Interestingly, the higher risk for TLF with BVS was mainly driven by more frequent ID-TLR and target vessel MI and 
only two out of seven trials among those included in this study required per protocol a late angiography ${ }^{5,20}$. In this regard, the increased incidence of ST is an important driver of these adverse events. Compared to EES, the risk for TLF after BVS implantation increased slightly at 12 months and was significantly higher at 24 months. However, it should be noticed that these results were mostly observed in well-selected patients and lesions, since only one ${ }^{11}$ out of seven trials enrolled a relatively broad spectrum of PCI patients more similar to those encountered in routine practice. In this respect, the findings and the magnitude of the treatment effects observed in the present analysis should be interpreted with caution and are not generalisable to higher-risk subsets of patients.

Of concern, in PCI patients treated with BVS as compared to EES we observed an increase in the risk of ST, with a number needed to harm of 63 . The increased thrombotic risk after BVS implantation was already present at 12-month follow-up and became particularly high in the period beyond one year. Although the mortality rate was low, which prevents this meta-analysis from having sufficient assessment power for this event, an explanation of the lack of impact on mortality of increased risk of ST with BVS is difficult. However, the low number of events and the absence of a long-term follow-up certainly play an important role in this regard. These results merit careful discussion.

First, the occurrence of thrombotic events even $>12$ months after BVS implantation is in keeping with small observational series describing late adverse events at advanced stages of BVS resorption $^{27,28}$. Although it is intuitive to expect that adoption of BVS implantation protocols targeted at improving acute mechanical results may impact on short-term outcomes, whether such protocols can modify rates of late thrombotic events remains to be seen. In this regard, a recent post hoc analysis from the AIDA all-comers trial showed that even adhering to good implantation techniques failed to limit the higher thrombotic risk associated with $\mathrm{BVS}^{29}$. Second, it remains to be determined if the observed higher risk of ST with BVS is directly attributable to loss of integrity of the stent and/or prolapse within the vessel lumen. In some patients with very late $\mathrm{ST}^{30}$, intracoronary imaging of BVS-treated segments demonstrated scaffold discontinuities, malapposition and uncovered struts. Scaffold discontinuities are a relatively common finding during BVS degradation and the relationship to subsequent adverse events is somewhat unclear ${ }^{31}$. In this respect, ongoing studies of intravascular imaging (NCT02683356, NCT02466282, NCT02814578, NCT02894697, and NCT02831218) are likely to be of great value in understanding the late performance of BVS. Third, it is unknown whether this risk of late device thrombosis might be ameliorated by prescription of more potent or prolonged duration of DAPT, especially for certain high-risk subgroups of patients $^{32}$. This issue should be explored further with dedicated studies. For instance, one trial ${ }^{5}$ observed absence of late thrombotic events after BVS implantation in patients who never interrupted DAPT up to three years. In this meta-analysis, the risk of ST with BVS was significantly increased both at 12-month and at 24-month follow-up, irrespective of the proportions of patients on DAPT. Finally, the majority of BVS-treated patients suffering from very late ST presented with ST-elevation MI at the time of re-admission. In this respect, the higher risk of MI related to the target vessel treated with BVS as compared to EES found in this report seems attributable to some extent to these late thrombotic events, rather than to periprocedural MI.

\section{Study limitations}

The current study has a number of limitations. First, as clinical outcomes in important subgroups were not consistently reported in included trials, an individual patient data meta-analysis is required to determine whether findings vary across different subgroups of patients. Second, the majority of included trials were available as meeting presentations and not as full-length manuscripts. Third, the actual duration of DAPT was not systematically monitored in all trials, precluding firm conclusions regarding a potential benefit of prolonged DAPT or more potent antiplatelet agents for BVStreated patients. Fourth, this study focused only on a single type of bioresorbable scaffold and current findings do not apply to other bioresorbable platforms. Finally, the assessment of publication bias was based on a limited number of trials: this resulted in low power and diminished performance of the asymmetry test.

\section{Conclusions}

The results of our meta-analysis suggest that percutaneous coronary intervention with BVS as compared to EES is associated with a higher risk of target lesion failure and myocardial infarction at a median follow-up longer than two years. The risk of definite/ probable ST is also higher with BVS as compared to EES, particularly in the period beyond one year after implantation. Future studies should investigate the influence of specific implantation protocols and more potent and/or prolonged dual antiplatelet therapy on overall clinical outcomes.

\section{Impact on daily practice}

The results of our meta-analysis suggest that a percutaneous coronary intervention with bioresorbable vascular scaffolds as compared to everolimus-eluting metallic stents is associated with a higher risk of serious adverse events at a median followup longer than two years. Whether the iterative development of fully bioresorbable scaffolds with improved mechanical and biological properties, the cautious selection of patients and lesions suitable for this technology, the adoption of specific implantation protocols and more potent and/or prolonged dual antiplatelet therapy would impact on clinical outcomes should be the object of future investigations.

\section{Guest Editor}

This paper was guest edited by Fernando Alfonso, MD, PhD, FESC; Department of Cardiology, Hospital Universitario de La Princesa, Universidad Autónoma de Madrid, Madrid, Spain. 


\section{Conflict of interest statement}

R. Byrne reports receiving lecture fees from B. Braun Melsungen AG, Biotronik and Boston Scientific and research grants to the institution from Boston Scientific and HeartFlow, outside the submitted work. P. Jüni has received research grants to the institution from AstraZeneca, Biotronik, Biosensors International, Eli Lilly and The Medicines Company outside the submitted work, and serves as an unpaid member of the steering group of trials funded by AstraZeneca, Biotronik, Biosensors, St. Jude Medical and The Medicines Company. J. Wykrzykowska reports receiving consultancy fees and research grants from Abbott Vascular, outside the submitted work. T. Kimura is a member of the International Advisory Board of Abbott. J. Henriques reports receiving research grants from Abbott Vascular, outside the submitted work. P. Serruys is a member of the International Advisory Board of Abbott. S. Windecker has received research contracts to the institution from Abbott, Boston Scientific, Biotronik, Edwards Lifesciences, Medtronic, and St. Jude, outside the submitted work. A. Kastrati reports holding patents related to drug-eluting stent technology, outside the submitted work. The other authors have no conflicts of interest to declare. The Guest Editor has no conflicts of interest to declare.

\section{References}

1. Steinvil A, Rogers T, Torguson R, Waksman R. Overview of the 2016 U.S. Food and Drug Administration Circulatory System Devices Advisory Panel Meeting on the Absorb Bioresorbable Vascular Scaffold System. JACC Cardiovasc Interv. 2016;9: 1757-64.

2. Kereiakes DJ, Onuma Y, Serruys PW, Stone GW. Bioresorbable Vascular Scaffolds for Coronary Revascularization. Circulation. 2016;134:168-82.

3. Cassese S, Byrne RA, Ndrepepa G, Kufner S, Wiebe J, Repp J, Schunkert H, Fusaro M, Kimura T, Kastrati A. Everolimuseluting bioresorbable vascular scaffolds versus everolimus-eluting metallic stents: a meta-analysis of randomised controlled trials. Lancet. 2016;387:537-44.

4. Byrne RA, Joner M, Kastrati A. Stent thrombosis and restenosis: what have we learned and where are we going? The Andreas Gruntzig Lecture ESC 2014. Eur Heart J. 2015;36:3320-31.

5. Serruys PW, Chevalier B, Sotomi Y, Cequier A, Carrié D, Piek JJ, Van Boven AJ, Dominici M, Dudek D, McClean D, Helqvist S, Haude M, Reith S, de Sousa Almeida M, Campo G, Iniguez A, Sabaté M, Windecker S, Onuma Y. Comparison of an everolimus-eluting bioresorbable scaffold with an everolimus-eluting metallic stent for the treatment of coronary artery stenosis (ABSORB II): a 3 year, randomised, controlled, single-blind, multicentre clinical trial. Lancet. 2016;388:2479-91.

6. Higgins JP, Altman DG, Gotzsche PC, Jüni P, Moher D, Oxman AD, Savovic J, Schulz KF, Weeks L, Sterne JA; Cochrane Bias Methods Group; Cochrane Statistical Methods Group. The Cochrane Collaboration's tool for assessing risk of bias in randomised trials. BMJ. 2011;343:d5928.
7. Jüni $P$, Witschi A, Bloch R, Egger $M$. The hazards of scoring the quality of clinical trials for meta-analysis. JAMA. 1999;282: 1054-60.

8. Hartung J, Knapp G. A refined method for the meta-analysis of controlled clinical trials with binary outcome. Stat Med. 2001;20:3875-89.

9. Wiksten A, Rücker G, Schwarzer G. Hartung-Knapp method is not always conservative compared with fixed-effect meta-analysis. Stat Med. 2016;35:2503-15.

10. Smeeth L, Haines A, Ebrahim S. Numbers needed to treat derived from meta-analyses--sometimes informative, usually misleading. BMJ. 1999;318:1548-51.

11. Wykrzykowska JJ, Kraak RP, Hofma SH, van der Schaaf RJ, Arkenbout EK, IJsselmuiden AJ, Elias J, van Dongen IM, Tijssen RYG, Koch KT, Baan J Jr, Vis MM, de Winter RJ, Piek JJ, Tijssen JGP, Henriques JPS; AIDA Investigators. Bioresorbable Scaffolds versus Metallic Stents in Routine PCI. $N$ Engl J Med. 2017;376:2319-28.

12. Higgins JP, Thompson SG, Deeks JJ, Altman DG. Measuring inconsistency in meta-analyses. BMJ. 2003;327:557-60.

13. Harbord RM, Egger M, Sterne JA. A modified test for smallstudy effects in meta-analyses of controlled trials with binary endpoints. Stat Med. 2006;25:3443-57.

14. Turner RM, Bird SM, Higgins JP. The impact of study size on meta-analyses: examination of underpowered studies in Cochrane reviews. PLoS One. 2013;8:e59202.

15. Moher D, Liberati A, Tetzlaff J, Altman DG; PRISMA Group. Preferred reporting items for systematic reviews and meta-analyses: the PRISMA statement. Ann Intern Med. 2009;151:264-9, W64.

16. Puricel S. Comparison of Everolimus-and Biolimus-Eluting Coronary Stents With Everolimus-Eluting Bioresorbable Vascular Scaffolds: 2-year Outcomes of the EVERBIO II Trial. Transcatheter Cardiovascular Therapeutics Congress 2015; oral presentation on October 14: San Francisco, CA, USA.

17. Windecker S. Comparison of the ABSORB Everolimus Eluting Bioresorbable Vascular Scaffold System With a DrugEluting Metal Stent (XIENCETM) in acute ST-Elevation Myocardial Infarction: 2-year results of TROFI II. Transcatheter Cardiovascular Therapeutics Congress 2016; oral presentation on October 31: Washington DC, USA.

18. Gao R. Randomized comparison of everolimus-eluting bioresorbable vascular scaffolds vs. everolimus-eluting metallic stents in patients with coronary artery disease: 3-year clinical outcomes from ABSORB China. EuroPCR Congress 2017; oral presentation on May 16: Paris, France.

19. Ellis SG, Kereiakes DJ, Stone GW; for the ABSORB III Investigators. Everolimus-eluting Bioresorbable Vascular Scaffolds in Patients with Coronary Artery Disease: ABSORB III Trial 2-Year Results. American College of Cardiology Congress 2017; oral presentation on March 19: Washington DC, USA.

20. Kozuma K. ABSORB Japan: 3-year Clinical and Angiographic Results of a Randomized trial Evaluating the Absorb Bioresorbable Vascular Scaffold vs. Metallic Drug-eluting Stent in de novo Native 
Coronary Artery Lesions. EuroPCR Congress 2017; oral presentation on May 16: Paris, France.

21. Iqbal J, Onuma Y, Ormiston J, Abizaid A, Waksman R, Serruys P. Bioresorbable scaffolds: rationale, current status, challenges, and future. Eur Heart J. 2014;35:765-76.

22. Lipinski MJ, Escarcega RO, Baker NC, Benn HA, Gaglia MA Jr, Torguson R, Waksman R. Scaffold Thrombosis After Percutaneous Coronary Intervention With ABSORB Bioresorbable Vascular Scaffold: A Systematic Review and Meta-Analysis. JACC Cardiovasc Interv. 2016;9:12-24.

23. Cassese S, Kastrati A. Bioresorbable Vascular Scaffold Technology Benefits From Healthy Skepticism. J Am Coll Cardiol. 2016;67:932-5.

24. Puricel S, Cuculi F, Weissner M, Schmermund A, Jamshidi P, Nyffenegger T, Binder H, Eggebrecht H, Munzel T, Cook S, Gori T. Bioresorbable Coronary Scaffold Thrombosis: Multicenter Comprehensive Analysis of Clinical Presentation, Mechanisms, and Predictors. J Am Coll Cardiol. 2016;67:921-31.

25. Toyota T, Morimoto T, Shiomi H, Yoshikawa Y, Yaku H, Yamashita Y, Kimura T. Very Late Scaffold Thrombosis of Bioresorbable Vascular Scaffold: Systematic Review and a MetaAnalysis. JACC Cardiovasc Interv. 2017;10:27-37.

26. Sorrentino S, Giustino G, Mehran R, Kini AS, Sharma SK, Faggioni M, Farhan S, Vogel B, Indolfi C, Dangas GD. EverolimusEluting Bioresorbable Scaffolds versus Everolimus-Eluting Metallic Stents. J Am Coll Cardiol. 2017;69:3055-66.

27. Räber L, Brugaletta S, Yamaji K, O’Sullivan CJ, Otsuki S, Koppara T, Taniwaki M, Onuma Y, Freixa X, Eberli FR, Serruys PW, Joner M, Sabaté M, Windecker S. Very Late Scaffold Thrombosis: Intracoronary Imaging and Histopathological and Spectroscopic Findings. J Am Coll Cardiol. 2015;66:1901-14.

28. Sotomi Y, Suwannasom P, Serruys PW, Onuma Y. Possible mechanical causes of scaffold thrombosis: insights from case reports with intracoronary imaging. EuroIntervention. 2017;12:1747-56.

29. Wykrzykowska J, Kraak R, Tijssen R. Amsterdam Investigator-Initiated Absorb Strategy All-Comers Trial. EuroPCR Congress 2017; oral presentation on May 19: Paris, France.

30. Onuma Y, Sotomi Y, Shiomi H, Ozaki Y, Namiki A, Yasuda S, Ueno T, Ando K, Furuya J, Igarashi K, Kozuma K, Tanabe K, Kusano H, Rapoza R, Popma JJ, Stone GW, Simonton C, Serruys PW, Kimura T. Two-year clinical, angiographic, and serial optical coherence tomographic follow-up after implantation of an everolimus-eluting bioresorbable scaffold and an everolimus-eluting metallic stent: insights from the randomised ABSORB Japan trial. EuroIntervention. 2016;12:1090-101.
31. Onuma Y, Serruys PW, Muramatsu T, Nakatani S, van Geuns RJ, de Bruyne B, Dudek D, Christiansen E, Smits PC, Chevalier B, McClean D, Koolen J, Windecker S, Whitbourn R, Meredith I, Garcia-Garcia HM, Veldhof S, Rapoza R, Ormiston JA. Incidence and imaging outcomes of acute scaffold disruption and late structural discontinuity after implantation of the absorb Everolimus-Eluting fully bioresorbable vascular scaffold: optical coherence tomography assessment in the ABSORB cohort B Trial (A Clinical Evaluation of the Bioabsorbable Everolimus Eluting Coronary Stent System in the Treatment of Patients With De Novo Native Coronary Artery Lesions). JACC Cardiovasc Interv. 2014;7: 1400-11.

32. Capodanno D, Angiolillo DJ. Antiplatelet Therapy After Implantation of Bioresorbable Vascular Scaffolds: A Review of the Published Data, Practical Recommendations, and Future Directions. JACC Cardiovasc Interv. 2017;10:425-37.

\section{Supplementary data}

Supplementary Table 1. PRISMA checklist.

Supplementary Table 2. Main characteristics of trials included in the study.

Supplementary Table 3. Definitions of clinical outcomes according to protocols across trials included in the study.

Supplementary Table 4. Assessment of risk of bias of trials included in the study.

Supplementary Figure 1. PRISMA flow chart for the trial selection process.

Supplementary Figure 2. Forest plot for primary efficacy outcome at 12 months, 24 months and beyond 12 months with BVS versus EES.

Supplementary Figure 3. Forest plot for definite/probable stent (scaffold) thrombosis at 12 months, 24 months and beyond 12 months with BVS versus EES.

Supplementary Figure 4. Forest plot for definite and very late definite stent (scaffold) thrombosis with BVS versus EES.

Supplementary Figure 5. Forest plots for other secondary outcomes with BVS versus EES.

Supplementary Figure 6. Funnel plot and influence analysis for primary efficacy outcome.

Supplementary Figure 7. Funnel plot and influence analysis for primary safety outcome.

The supplementary data are published online at:

http://www.pcronline.com/

eurointervention/128th issue/252 


\section{Supplementary data}

Supplementary Table 1. PRISMA checklist.

\begin{tabular}{|c|c|c|c|}
\hline Section/topic & $\#$ & Checklist item & $\begin{array}{l}\text { Reported } \\
\text { on page \# }\end{array}$ \\
\hline \multicolumn{4}{|l|}{ TITLE } \\
\hline Title & 1 & Identify the report as a systematic review, meta-analysis, or both. & 1 \\
\hline \multicolumn{4}{|l|}{ ABSTRACT } \\
\hline Structured summary & 2 & $\begin{array}{l}\text { Provide a structured summary including, as applicable: background; objectives; data sources; study } \\
\text { eligibility criteria, participants, and interventions; study appraisal and synthesis methods; results; } \\
\text { limitations; conclusions and implications of key findings; systematic review registration number. }\end{array}$ & 3 \\
\hline \multicolumn{4}{|l|}{ INTRODUCTION } \\
\hline Rationale & 3 & Describe the rationale for the review in the context of what is already known. & 5 \\
\hline Objectives & 4 & $\begin{array}{l}\text { Provide an explicit statement of questions being addressed with reference to participants, interventions, } \\
\text { comparisons, outcomes, and study design (PICOS). }\end{array}$ & 5 \\
\hline \multicolumn{4}{|l|}{ METHODS } \\
\hline Protocol and registration & 5 & $\begin{array}{l}\text { Indicate if a review protocol exists, if and where it can be accessed (e.g., Web address), and, if available, } \\
\text { provide registration information including registration number. }\end{array}$ & 6 \\
\hline Eligibility criteria & 6 & $\begin{array}{l}\text { Specify study characteristics (e.g., PICOS, length of follow-up) and report characteristics (e.g., years } \\
\text { considered, language, publication status) used as criteria for eligibility, giving rationale. }\end{array}$ & 6 \\
\hline Information sources & 7 & $\begin{array}{l}\text { Describe all information sources (e.g., databases with dates of coverage, contact with study authors to } \\
\text { identify additional studies) in the search and date last searched. }\end{array}$ & 6 \\
\hline Search & 8 & $\begin{array}{l}\text { Present full electronic search strategy for at least one database, including any limits used, such that it could } \\
\text { be repeated. }\end{array}$ & 11, S-data \\
\hline Study selection & 9 & $\begin{array}{l}\text { State the process for selecting studies (i.e., screening, eligibility, included in systematic review, and, if } \\
\text { applicable, included in the meta-analysis). }\end{array}$ & 6 \\
\hline
\end{tabular}




\begin{tabular}{|c|c|c|c|}
\hline Data collection process & 10 & $\begin{array}{l}\text { Describe method of data extraction from reports (e.g., piloted forms, independently, in duplicate) and any } \\
\text { processes for obtaining and confirming data from investigators. }\end{array}$ & 6 \\
\hline Data items & 11 & $\begin{array}{l}\text { List and define all variables for which data were sought (e.g., PICOS, funding sources) and any } \\
\text { assumptions and simplifications made. }\end{array}$ & 6 \\
\hline $\begin{array}{l}\text { Risk of bias in individual } \\
\text { studies }\end{array}$ & 12 & $\begin{array}{l}\text { Describe methods used for assessing risk of bias of individual studies (including specification of whether } \\
\text { this was done at the study or outcome level), and how this information is to be used in any data synthesis. }\end{array}$ & 6 \\
\hline Summary measures & 13 & State the principal summary measures (e.g., risk ratio, difference in means). & 7 \\
\hline Synthesis of results & 14 & $\begin{array}{l}\text { Describe the methods of handling data and combining results of studies, if done, including measures of } \\
\text { consistency }\left(\text { e.g., } \mathrm{I}^{2}\right) \text { for each meta-analysis. }\end{array}$ & 7 \\
\hline Risk of bias across studies & 15 & $\begin{array}{l}\text { Specify any assessment of risk of bias that may affect the cumulative evidence (e.g., publication bias, } \\
\text { selective reporting within studies). }\end{array}$ & 7 \\
\hline Additional analyses & 16 & $\begin{array}{l}\text { Describe methods of additional analyses (e.g., sensitivity or subgroup analyses, meta-regression), if done, } \\
\text { indicating which were pre-specified. }\end{array}$ & 7 \\
\hline \multicolumn{4}{|l|}{ RESULTS } \\
\hline Study selection & 17 & $\begin{array}{l}\text { Give numbers of studies screened, assessed for eligibility, and included in the review, with reasons for } \\
\text { exclusions at each stage, ideally with a flow diagram. }\end{array}$ & 14, S-data \\
\hline Study characteristics & 18 & $\begin{array}{l}\text { For each study, present characteristics for which data were extracted (e.g., study size, PICOS, follow-up } \\
\text { period) and provide the citations. }\end{array}$ & $\begin{array}{l}\text { 2-3, } S- \\
\text { data }\end{array}$ \\
\hline Risk of bias within studies & 19 & Present data on risk of bias of each study and, if available, any outcome level assessment (see item 12). & 7, S-data \\
\hline $\begin{array}{l}\text { Results of individual } \\
\text { studies }\end{array}$ & 20 & $\begin{array}{l}\text { For all outcomes considered (benefits or harms), present, for each study: (a) simple summary data for each } \\
\text { intervention group (b) effect estimates and confidence intervals, ideally with a forest plot. }\end{array}$ & 23-27 \\
\hline Synthesis of results & 21 & Present results of each meta-analysis done, including confidence intervals and measures of consistency. & $10-12$ \\
\hline Risk of bias across studies & 22 & Present results of any assessment of risk of bias across studies (see item 15). & $\begin{array}{l}\text { 26-29, } S- \\
\text { data }\end{array}$ \\
\hline Additional analysis & 23 & $\begin{array}{l}\text { Give results of additional analyses, if done (e.g., sensitivity or subgroup analyses, meta-regression [see item } \\
\text { 16]). }\end{array}$ & 12 \\
\hline \multicolumn{4}{|l|}{ DISCUSSION } \\
\hline Summary of evidence & 24 & $\begin{array}{l}\text { Summarise the main findings including the strength of evidence for each main outcome; consider their } \\
\text { relevance to key groups (e.g., healthcare providers, users, and policy makers). }\end{array}$ & 12 \\
\hline
\end{tabular}




\begin{tabular}{|l|c|l|l|}
\hline Limitations & 25 & $\begin{array}{l}\text { Discuss limitations at study and outcome level (e.g., risk of bias), and at review level (e.g., incomplete } \\
\text { retrieval of identified research, reporting bias). }\end{array}$ & $\mathbf{1 5}$ \\
\hline Conclusions & 26 & $\begin{array}{l}\text { Provide a general interpretation of the results in the context of other evidence, and implications for future } \\
\text { research. }\end{array}$ & $\mathbf{1 6}$ \\
\hline \hline FUNDING & 27 & $\begin{array}{l}\text { Describe sources of funding for the systematic review and other support (e.g., supply of data); role of } \\
\text { funders for the systematic review. }\end{array}$ & 17 \\
\hline Funding
\end{tabular}


Supplementary Table 2. Main characteristics of trials included in the study.

\begin{tabular}{|c|c|c|c|c|c|c|c|}
\hline $\begin{array}{l}\text { Main } \\
\text { inclusion } \\
\text { criteria }\end{array}$ & $\begin{array}{l}\text { Age } \geq 18 \text { years; } \\
\text { evidence of } \\
\text { myocardial } \\
\text { ischaemia; } \leq 2 \text { de } \\
\text { novo coronary } \\
\text { lesions; reference } \\
\text { vessel diameter } \\
\geq 2.5 \text { and } \leq 3.75 \\
\mathrm{~mm} \text {; lesion length } \\
\leq 24 \mathrm{~mm}\end{array}$ & $\begin{array}{l}\text { Age } \geq 18 \text { and } \\
\leq 85 \text { years; } \\
\text { evidence of } \\
\text { myocardial } \\
\text { ischaemia; } \leq 2 \\
\text { de novo } \\
\text { coronary } \\
\text { lesions }\end{array}$ & $\begin{array}{l}\text { Age } \geq 18 \text { years; } \\
\text { evidence of } \\
\text { myocardial } \\
\text { ischaemia; } \leq 2 \text { de } \\
\text { novo coronary } \\
\text { lesions; reference } \\
\text { vessel diameter } \\
\geq 2.5 \text { and } \leq 3.75 \\
\mathrm{~mm} \text {; lesion length } \\
\leq 24 \mathrm{~mm}\end{array}$ & $\begin{array}{l}\text { Age } \geq 20 \text { years; } \\
\text { evidence of } \\
\text { myocardial } \\
\text { ischaemia; } \leq 2 \text { de } \\
\text { novo coronary } \\
\text { lesions; reference } \\
\text { vessel diameter } \\
\geq 2.5 \text { and } \leq 3.75 \\
\mathrm{~mm} \text {; lesion length } \\
\leq 24 \mathrm{~mm}\end{array}$ & $\begin{array}{l}\text { Age } \geq 18 \text { years; } \\
\text { acceptable DES } \\
\text { candidate according } \\
\text { to PCI guidelines } \\
\text { and IFU of devices } \\
\text { under investigation }\end{array}$ & $\begin{array}{l}\text { Age } \geq 18 \text { years; } \\
\text { stable or unstable } \\
\text { ischaemic heart } \\
\text { disease }\end{array}$ & $\begin{array}{l}\text { Age } \geq 18 \text { years; } \\
\text { STEMI } \leq 24 \text { hrs } \\
\text { after the } \\
\text { symptoms onset } \\
\text { requiring } \\
\text { emergent PCI; } \\
\text { reference vessel } \\
\text { diameter } \geq 2.25 \\
\text { and } \leq 3.8 \mathrm{~mm}\end{array}$ \\
\hline $\begin{array}{l}\text { Main } \\
\text { exclusion } \\
\text { criteria }\end{array}$ & $\begin{array}{l}\text { Acute MI; recent } \\
\text { MI without } \\
\text { normalised cardiac } \\
\text { markers; LVEF } \\
\leq 30 \% \text {; previous } \\
\text { PCI in the target } \\
\text { vessel } \leq 1 \text { year; left } \\
\text { main stenosis; } \\
\text { bifurcation lesion } \\
\text { with a side branch } \\
\text { diameter > } 2.0 \text { mm; } \\
\text { ostial lesion; } \\
\text { moderate/heavy } \\
\text { calcified lesion; } \\
\text { thrombotic lesion }\end{array}$ & $\begin{array}{l}\text { Acute MI; } \\
\text { recent MI } \\
\text { without } \\
\text { normalised } \\
\text { cardiac } \\
\text { markers; LVEF } \\
\leq 30 \%\end{array}$ & $\begin{array}{l}\text { Acute MI; recent } \\
\text { MI without } \\
\text { normalised cardiac } \\
\text { markers; LVEF } \\
\leq 30 \% \text {; previous } \\
\text { PCI in the target } \\
\text { vessel } \leq 1 \text { year; left } \\
\text { main stenosis; } \\
\text { bifurcation lesion } \\
\text { with a side branch } \\
\text { diameter > } 2.0 \text { mm; } \\
\text { ostial lesion; } \\
\text { moderate/heavy } \\
\text { calcified lesion; } \\
\text { thrombotic lesion }\end{array}$ & $\begin{array}{l}\text { Recent MI; LVEF } \\
\leq 30 \% \text {; estimated } \\
\text { glomerular } \\
\text { filtration rate <30 } \\
\mathrm{mL} / \mathrm{min} / 1.73 \mathrm{~m}^{2} ; \\
\text { high bleeding risk; } \\
\text { left main stenosis; } \\
\text { excessive vessel } \\
\text { tortuosity; } \\
\text { bifurcation lesion } \\
\text { with a side branch } \\
\text { diameter >2.0 mm; } \\
\text { ostial lesion; } \\
\text { moderate/heavy } \\
\text { calcified lesion; } \\
\text { thrombotic lesion; } \\
\text { restenotic lesion }\end{array}$ & $\begin{array}{l}\text { In-stent restenosis; } \\
\text { reference vessel } \\
\text { diameter <2.5 and } \\
>4.0 \mathrm{~mm} \text {; planned } \\
\text { stented length > } 70 \\
\text { mm; true } \\
\text { bifurcation lesion } \\
\text { with a planned two- } \\
\text { device strategy; } \\
\text { known or presumed } \\
\text { hypersensitivity to } \\
\text { heparin, } \\
\text { bivalirudin, } \\
\text { antiplatelet drugs, } \\
\text { stent/scaffold } \\
\text { components, or } \\
\text { contrast dye not }\end{array}$ & $\begin{array}{l}\text { Reference vessel } \\
\text { diameter } \geq 4.0 \\
\text { mm; known or } \\
\text { presumed } \\
\text { hypersensitivity } \\
\text { to heparin, } \\
\text { antiplatelet drugs, } \\
\text { or contrast dye } \\
\text { not controllable } \\
\text { with standard } \\
\text { premedication }\end{array}$ & $\begin{array}{l}\text { Cardiogenic } \\
\text { shock; severe } \\
\text { tortuosity or } \\
\text { calcification; } \\
\text { inadequate } \\
\text { vessel size }\end{array}$ \\
\hline
\end{tabular}




\begin{tabular}{|c|c|c|c|c|c|c|c|}
\hline & & & & & $\begin{array}{l}\text { controllable with } \\
\text { standard } \\
\text { premedication }\end{array}$ & & \\
\hline $\begin{array}{l}\text { Primary } \\
\text { endpoints }\end{array}$ & $\begin{array}{l}\text { 12-month in- } \\
\text { segment LLL }\end{array}$ & $\begin{array}{l}\text { 36-month } \\
\text { coronary } \\
\text { vasomotion and } \\
\text { MLD }\end{array}$ & 12-month TLF & 12-month TLF & 24-month TVF & $\begin{array}{l}\text { 9-month in- } \\
\text { device LLL }\end{array}$ & $\begin{array}{l}\text { 6-month healing } \\
\text { score }\end{array}$ \\
\hline $\begin{array}{l}\text { Longest } \\
\text { follow-up } \\
\text { available }\end{array}$ & 36 months & 36 months & 25 months & 36 months & 24 months* & 24 months & 24 months \\
\hline $\begin{array}{l}\text { Registration } \\
\text { number }\end{array}$ & NCT01923740 & NCT01425281 & NCT01751906 & NCT01844284 & NCT01858077 & NCT01711931 & NCT01986803 \\
\hline
\end{tabular}

* median duration.

LLL: late lumen loss; LVEF: left ventricular ejection fraction; MI: myocardial infarction; MLD: minimal lumen diameter; PCI: percutaneous coronary intervention; STEMI: ST-elevated myocardial infarction; TL(V)F: target lesion (vessel) failure.

Official titles and acronyms: ABSORB China: A Clinical Evaluation of Absorb ${ }^{\mathrm{TM}}$ Bioresorbable Vascular Scaffold (Absorb ${ }^{\mathrm{TM}}$ BVS) System in Chinese Population; ABSORB II: A Clinical Evaluation to Compare the Safety, Efficacy and Performance of ABSORB Everolimus Eluting Bioresorbable Vascular Scaffold System Against XIENCE Everolimus Eluting Coronary Stent System in the Treatment of Subjects With Ischemic Heart Disease Caused by de Novo Native Coronary Artery Lesions; ABSORB III: A Clinical Evaluation of Absorb ${ }^{\mathrm{TM}}$ BVS, the Everolimus Eluting Bioresorbable Vascular Scaffold in the Treatment of Subjects With de Novo Native Coronary Artery Lesions; ABSORB Japan: A Clinical Evaluation of AVJ-301 (Absorb ${ }^{\mathrm{TM}}$ BVS), the Everolimus Eluting Bioresorbable Vascular Scaffold in the Treatment of Subjects With de Novo 
Native Coronary Artery Lesions in Japanese Population; AIDA: Amsterdam Investigator-initiateD Absorb strategy all-comers trial; EVERBIO II: Comparison of Everolimus- and Biolimus-Eluting Stents With Everolimus-Eluting Bioresorbable Vascular Scaffold Stents; TROFI II: Comparison of the ABSORB ${ }^{\mathrm{TM}}$ Everolimus Eluting Bioresorbable Vascular Scaffold System With a Drug- Eluting Metal Stent (XIENCE ${ }^{\mathrm{TM}}$ ) in Acute ST-

Elevation Myocardial Infarction. 
Supplementary Table 3. Definitions of clinical outcomes according to protocols across trials included in the study.

\begin{tabular}{|c|c|c|c|c|c|c|c|}
\hline & $\begin{array}{l}\text { ABSORB } \\
\text { China }\end{array}$ & ABSORB II & ABSORB III & $\begin{array}{l}\text { ABSORB } \\
\text { Japan }\end{array}$ & AIDA & EVERBIO II & TROFI II \\
\hline $\begin{array}{l}\text { Target lesion } \\
\text { failure }\end{array}$ & $\begin{array}{l}\text { Cardiac death; } \\
\text { target vessel } \\
\text { MI; ID-TLR }\end{array}$ & $\begin{array}{l}\text { Cardiac death; } \\
\text { target vessel } \\
\text { MI; ID-TLR }\end{array}$ & $\begin{array}{l}\text { Cardiac death; } \\
\text { target vessel MI; } \\
\text { ID-TLR }\end{array}$ & $\begin{array}{l}\text { Cardiac death; } \\
\text { target vessel } \\
\text { MI; ID-TLR }\end{array}$ & $\begin{array}{l}\text { Cardiac death; } \\
\text { target vessel MI; } \\
\text { ID-TLR }\end{array}$ & $\begin{array}{l}\text { Cardiac death; } \\
\text { MI; TLR }\end{array}$ & $\begin{array}{l}\text { Cardiac death; MI not } \\
\text { clearly attributable to } \\
\text { a non-intervention } \\
\text { vessel; ID-TLR }\end{array}$ \\
\hline $\begin{array}{l}\text { Scaffold/stent } \\
\text { thrombosis }\end{array}$ & ARC definitions & ARC definitions & ARC definitions & ARC definitions & ARC definitions & ARC definitions & ARC definitions \\
\hline $\begin{array}{l}\text { Target lesion } \\
\text { revascularisation }\end{array}$ & $\begin{array}{l}\text { Any ischaemia- } \\
\text { driven repeat } \\
\text { percutaneous } \\
\text { intervention of } \\
\text { the target lesion } \\
\text { or bypass } \\
\text { surgery of the } \\
\text { target vessel }\end{array}$ & $\begin{array}{l}\text { Any clinically } \\
\text { indicated repeat } \\
\text { percutaneous } \\
\text { intervention of } \\
\text { the target lesion } \\
\text { or bypass } \\
\text { surgery of the } \\
\text { target vessel }\end{array}$ & $\begin{array}{l}\text { Any repeat } \\
\text { percutaneous } \\
\text { intervention of } \\
\text { the target lesion } \\
\text { or bypass } \\
\text { surgery of the } \\
\text { target vessel } \\
\text { performed for } \\
\text { restenosis or } \\
\text { other } \\
\text { complication of } \\
\text { the target lesion }\end{array}$ & $\begin{array}{l}\text { Any ischaemia- } \\
\text { driven repeat } \\
\text { percutaneous } \\
\text { intervention of } \\
\text { the target lesion } \\
\text { or bypass } \\
\text { surgery of the } \\
\text { target vessel }\end{array}$ & $\begin{array}{l}\text { Any clinically } \\
\text { indicated repeat } \\
\text { percutaneous } \\
\text { intervention of } \\
\text { the target lesion } \\
\text { or bypass } \\
\text { surgery of the } \\
\text { target vessel }\end{array}$ & $\begin{array}{l}\text { Any repeat } \\
\text { revascularisation } \\
\text { within the } \\
\text { stent/scaffold or } \\
\text { the } 5 \text {-mm } \\
\text { borders proximal } \\
\text { and distal to the } \\
\text { device }\end{array}$ & $\begin{array}{l}\text { Any clinically } \\
\text { indicated repeat } \\
\text { percutaneous } \\
\text { intervention of the } \\
\text { target lesion or bypass } \\
\text { surgery of the target } \\
\text { vessel }\end{array}$ \\
\hline $\begin{array}{l}\text { Myocardial } \\
\text { infarction }\end{array}$ & $\begin{array}{l}\text { Periprocedural: } \\
\text { CK-MB >5x } \\
\text { ULN. } \\
\text { Spontaneous: } \\
\text { Troponin >ULN } \\
\text { or CK-MB } \\
>\mathrm{ULN} \geq 1 \text { of the } \\
\text { following: } \\
\text { ischaemic }\end{array}$ & $\begin{array}{l}\text { New } \\
\text { pathological Q- } \\
\text { waves in } \geq 2 \\
\text { contiguous } \\
\text { leads with or } \\
\text { without increase } \\
\text { of cardiac } \\
\text { enzymes or } \\
\text { increase of CK }\end{array}$ & $\begin{array}{l}\text { Periprocedural: } \\
\text { CK-MB >5x } \\
\text { ULN. } \\
\text { Spontaneous: } \\
\text { Troponin >ULN } \\
\text { or CK-MB } \\
>\mathrm{ULN} \geq 1 \text { of the } \\
\text { following: } \\
\text { ischaemic }\end{array}$ & $\begin{array}{l}\text { Periprocedural: } \\
\text { CK-MB >5x } \\
\text { ULN. } \\
\text { Spontaneous: } \\
\text { Troponin >ULN } \\
\text { or CK-MB } \\
>\mathrm{ULN} \text { and } \geq 1 \\
\text { of the } \\
\text { following: }\end{array}$ & $\begin{array}{l}\text { Periprocedural: } \\
\text { CK-MB }>5 \mathrm{x} \\
\text { ULN. } \\
\text { Spontaneous: } \\
\text { Troponin >ULN } \\
\text { or CK-MB } \\
>\mathrm{ULN} \geq 1 \text { of the } \\
\text { following: } \\
\text { ischaemic }\end{array}$ & $\begin{array}{l}\text { Periprocedural: } \\
\text { CK-MB >5x } \\
\text { ULN. } \\
\text { Spontaneous: } \\
\text { development of } \\
\text { new pathological } \\
\text { Q-waves }>0.04 \mathrm{~s} \\
\text { in duration in } \geq 2 \\
\text { contiguous leads }\end{array}$ & $\begin{array}{l}\text { Periprocedural: CK- } \\
\text { MB >5x ULN. } \\
\text { Spontaneous: new } \\
\text { pathological Q-waves } \\
\text { in } \geq 2 \text { contiguous leads } \\
\text { (as assessed by the } \\
\text { ECG core laboratory) } \\
\text { with or without post- } \\
\text { procedure troponin, }\end{array}$ \\
\hline
\end{tabular}




\begin{tabular}{|c|c|c|c|c|c|c|c|}
\hline & $\begin{array}{l}\text { symptoms, } \\
\text { ischaemic ECG } \\
\text { changes, } \\
\text { development of } \\
\text { pathological Q- } \\
\text { waves, or } \\
\text { imaging } \\
\text { findings of an } \\
\text { acute MI }\end{array}$ & $\begin{array}{l}\text { to }>2 \text { times } \\
\text { ULN, with a } \\
\text { concomitant } \\
\text { increase in the } \\
\text { MB isoenzyme } \\
\text { fraction without } \\
\text { new } \\
\text { pathological Q- } \\
\text { waves }\end{array}$ & $\begin{array}{l}\text { symptoms, } \\
\text { ischaemic ECG } \\
\text { changes, } \\
\text { development of } \\
\text { pathological Q- } \\
\text { waves, or } \\
\text { imaging } \\
\text { findings of an } \\
\text { acute MI }\end{array}$ & $\begin{array}{l}\text { ischaemic } \\
\text { symptoms, } \\
\text { ischaemic ECG } \\
\text { changes, } \\
\text { development of } \\
\text { pathological Q- } \\
\text { waves, or } \\
\text { imaging } \\
\text { findings of an } \\
\text { acute MI }\end{array}$ & $\begin{array}{l}\text { symptoms, } \\
\text { ischaemic ECG } \\
\text { changes, } \\
\text { development of } \\
\text { pathological Q- } \\
\text { waves, or } \\
\text { imaging findings } \\
\text { of an acute MI }\end{array}$ & $\begin{array}{l}\text { or an elevation } \\
\text { of CK levels to } \\
>2 \text { times ULN } \\
\text { with positive } \\
\text { CK-MB or } \\
\text { troponin I levels }\end{array}$ & $\begin{array}{l}\text { CK or CK-MB levels } \\
\text { elevated }>\text { ULN (Q- } \\
\text { wave MI); rise and/or } \\
\text { fall of cardiac } \\
\text { biomarker values } \\
\text { (preferably cardiac } \\
\text { troponin) with at } \geq 1 \\
\text { value }>\text { ULN and with } \\
\geq 1 \text { of the following: } \\
\text { ischaemic symptoms, } \\
\text { ischaemic ECG } \\
\text { changes, or } \\
\text { imaging/pathological } \\
\text { findings of an acute } \\
\text { MI (non-Q-wave } \\
\text { MI)* }\end{array}$ \\
\hline
\end{tabular}


*given the acute clinical setting the definition of reinfarction was also reported in the original trial; for official titles and acronyms see

Supplementary Table 1 .

ARC: Academic Research Consortium; CK-(MB): creatine kinase (myocardial band); (ID)-TLR: (ischaemia-driven) target lesion revascularisation;

MI: myocardial infarction; ULN: upper level of normal 
Supplementary Table 4. Assessment of risk of bias of trials included in the study.

\begin{tabular}{|c|c|c|c|c|c|c|c|}
\hline & $\begin{array}{l}\text { ABSORB } \\
\text { China }\end{array}$ & ABSORB II & ABSORB III & $\begin{array}{l}\text { ABSORB } \\
\text { Japan }\end{array}$ & AIDA & EVERBIO II & TROFI II \\
\hline $\begin{array}{l}\text { Random sequence } \\
\text { generation }\end{array}$ & Yes & $\begin{array}{l}\text { Yes } \\
(\text { IWRS) }\end{array}$ & $\begin{array}{l}\text { Yes } \\
\text { (IWRS) }\end{array}$ & $\begin{array}{l}\text { Yes } \\
(\text { IWRS) }\end{array}$ & $\begin{array}{l}\text { Yes } \\
\text { (IWRS) }\end{array}$ & $\begin{array}{l}\text { Yes } \\
\text { (central random } \\
\text { list) }\end{array}$ & $\begin{array}{l}\text { Yes } \\
\text { (web-based } \\
\text { software) }\end{array}$ \\
\hline Allocation concealment & Yes & Yes & Yes & Yes & Yes & Yes & Yes \\
\hline Blinding of participants & No & Yes & Yes & Yes & Yes & No & Yes \\
\hline $\begin{array}{l}\text { Blinding of outcome } \\
\text { assessment }\end{array}$ & $\begin{array}{l}\text { Yes } \\
\text { (Independent } \\
\text { CEC) }\end{array}$ & $\begin{array}{l}\text { Yes } \\
\text { (Independent } \\
\text { CEC) }\end{array}$ & $\begin{array}{l}\text { Yes } \\
\text { (Independent } \\
\text { CEC) }\end{array}$ & $\begin{array}{l}\text { Yes } \\
\text { (Independent } \\
\text { CEC) }\end{array}$ & $\begin{array}{l}\text { Yes } \\
\text { (Independent } \\
\text { CEC) }\end{array}$ & $\begin{array}{l}\text { Yes } \\
\text { (Independent } \\
\text { CEC) }\end{array}$ & $\begin{array}{l}\text { Yes } \\
\text { (Independent } \\
\text { CEC) }\end{array}$ \\
\hline $\begin{array}{l}\text { Description of } \\
\text { incomplete outcome data }\end{array}$ & $\begin{array}{l}\text { Yes } \\
\text { (flow diagram) }\end{array}$ & $\begin{array}{l}\text { Yes } \\
\text { (flow diagram) }\end{array}$ & $\begin{array}{l}\text { Yes (flow } \\
\text { diagram) }\end{array}$ & $\begin{array}{l}\text { Yes } \\
\text { (flow diagram) }\end{array}$ & $\begin{array}{l}\text { Yes } \\
\text { (flow diagram) }\end{array}$ & $\begin{array}{l}\text { Yes } \\
\text { (flow diagram) }\end{array}$ & $\begin{array}{l}\text { Yes } \\
\text { (flow diagram) }\end{array}$ \\
\hline $\begin{array}{l}\text { Selective outcome } \\
\text { reporting }\end{array}$ & No & No & No & No & No & No & No \\
\hline Sample size calculation & $\begin{array}{l}\text { Yes } \\
\text { (non- } \\
\text { inferiority) }\end{array}$ & $\begin{array}{l}\text { Yes } \\
\text { (superiority)* }\end{array}$ & $\begin{array}{l}\text { Yes } \\
\text { (non- } \\
\text { inferiority) }\end{array}$ & $\begin{array}{l}\text { Yes } \\
\text { (non- } \\
\text { inferiority) }\end{array}$ & $\begin{array}{l}\text { Yes } \\
\text { (non-inferiority) }\end{array}$ & $\begin{array}{l}\text { Yes } \\
\text { (superiority) } \dagger\end{array}$ & $\begin{array}{l}\text { Yes } \\
\text { (non-inferiority) }\end{array}$ \\
\hline Sponsor & $\begin{array}{l}\text { Industry- } \\
\text { initiated }\end{array}$ & $\begin{array}{l}\text { Industry- } \\
\text { initiated }\end{array}$ & $\begin{array}{l}\text { Industry- } \\
\text { initiated }\end{array}$ & $\begin{array}{l}\text { Industry- } \\
\text { initiated }\end{array}$ & $\begin{array}{l}\text { Investigator- } \\
\text { initiated }\end{array}$ & $\begin{array}{l}\text { Investigator- } \\
\text { initiated }\end{array}$ & $\begin{array}{l}\text { Investigator- } \\
\text { initiated }\end{array}$ \\
\hline
\end{tabular}

*for the primary outcome of 36-month coronary vasomotion; $\uparrow$ for comparison of metallic drug-eluting stent (two arms) versus bioresorbable scaffold; for official titles and acronyms see Supplementary Table 1.

CEC: clinical events committee; IWRS: interactive web-based response system 


\section{Supplementary Figure Legends:}

Supplementary Figure 1. PRISMA flow chart for the trial selection process.

PRISMA: Preferred Reporting Items for Systematic reviews and Meta-Analyses.

BVS: bioresorbable vascular scaffold; EES: everolimus-eluting stent; RCTs: randomised controlled trials

Supplementary Figure 2. Forest plot for primary efficacy outcome at 12 months, 24 months and beyond 12 months with BVS versus EES.

Odds ratios for target lesion failure at 12 months, 24 months and beyond 12 months with BVS versus EES (A-C). The diamonds indicate the point estimates and the left and the right ends of the lines the $95 \%$ confidence intervals.

BVS: bioresorbable vascular scaffold; EES: everolimus-eluting stent

Supplementary Figure 3. Forest plot for definite/probable stent (scaffold) thrombosis at 12 months, 24 months and beyond 12 months with BVS versus EES.

Odds ratios for definite/probable stent (scaffold) thrombosis at 12 and 24 months and beyond 12 months with BVS versus EES (A-C). The diamonds indicate the point estimates and the left and the right ends of the lines the $95 \%$ confidence intervals.

BVS: bioresorbable vascular scaffold; EES: everolimus-eluting stent

Supplementary Figure 4. Forest plot for definite and very late definite stent (scaffold) thrombosis with BVS versus EES. 
Odds ratio for definite (A) and very late definite (B) stent (scaffold) thrombosis with BVS versus EES. The diamonds indicate the point estimates and the left and the right ends of the lines the $95 \%$ confidence intervals.

BVS: bioresorbable vascular scaffold; EES: everolimus-eluting stent

Supplementary Figure 5. Forest plots for other secondary outcomes with BVS versus EES.

Odds ratios for death (A), myocardial infarction (B), target lesion revascularisation (C) and any revascularisation (D) with BVS versus EES. The diamonds indicate the point estimates and the left and the right ends of the lines the $95 \%$ confidence intervals.

BVS: bioresorbable scaffold; EES: everolimus-eluting stent

Supplementary Figure 6. Funnel plot and influence analysis for primary efficacy outcome.

A) The publication bias is evaluated both visually and with an asymmetry test. A p-value $<0.05$ indicates significance.

B) Meta-analysis of random effects estimates for target lesion failure computed omitting one study at a time.

Supplementary Figure 7. Funnel plot and influence analysis for primary safety outcome.

A) The publication bias is evaluated both visually and with an asymmetry test. A p-value $<0.05$ indicates significance.

B) Meta-analysis of random effects estimates for definite/probable stent (scaffold) thrombosis computed omitting one study at a time. 


\section{Supplementary Figures}

Records identified through database searching (PubMed, EMBASE, CENTRAL, $n=162$ ) Additional records identified through other sources (Meeting abstracts, relevant websites, $n=98$ )

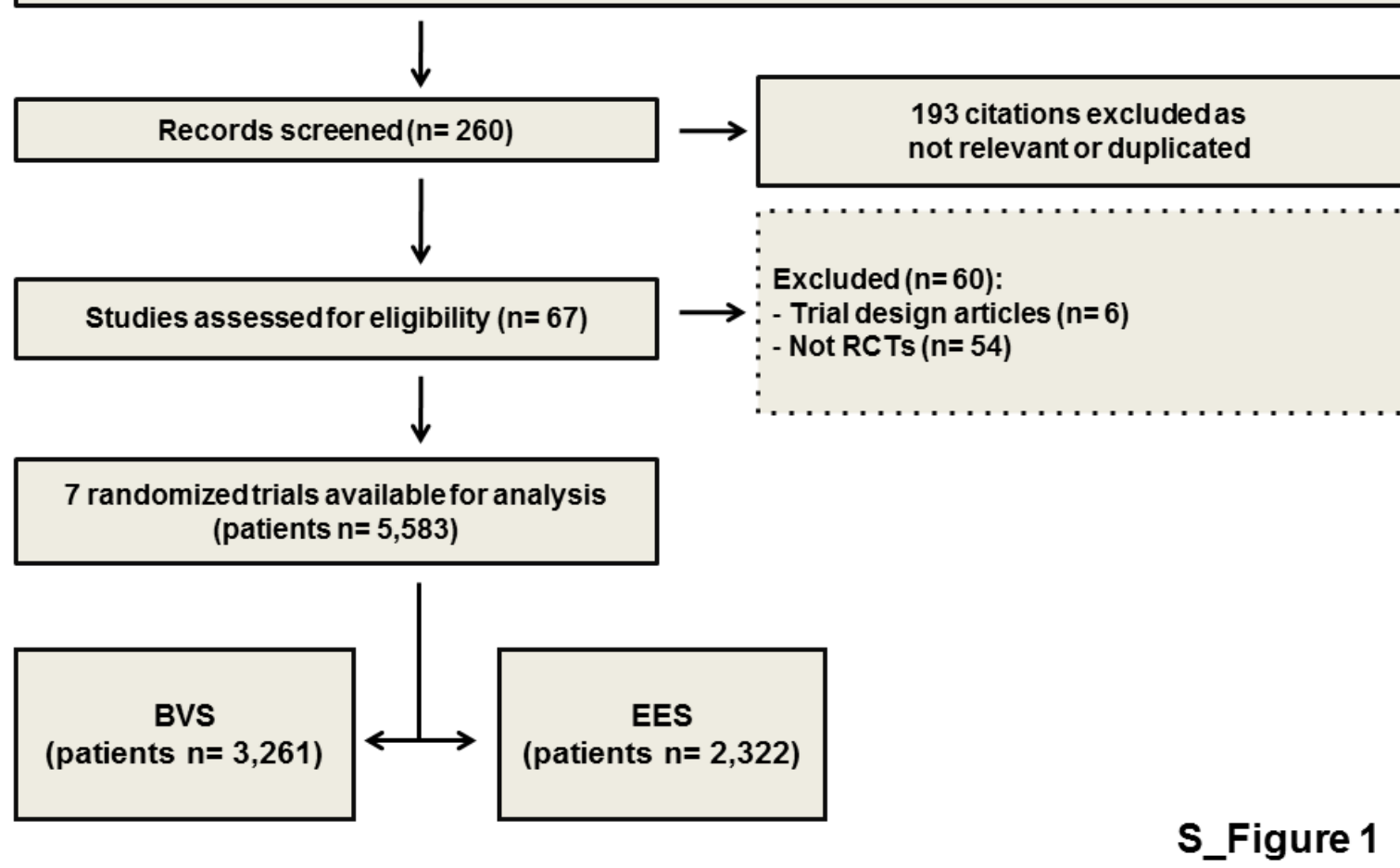




\section{Target lesion failure at $\mathbf{1 2}$ months}

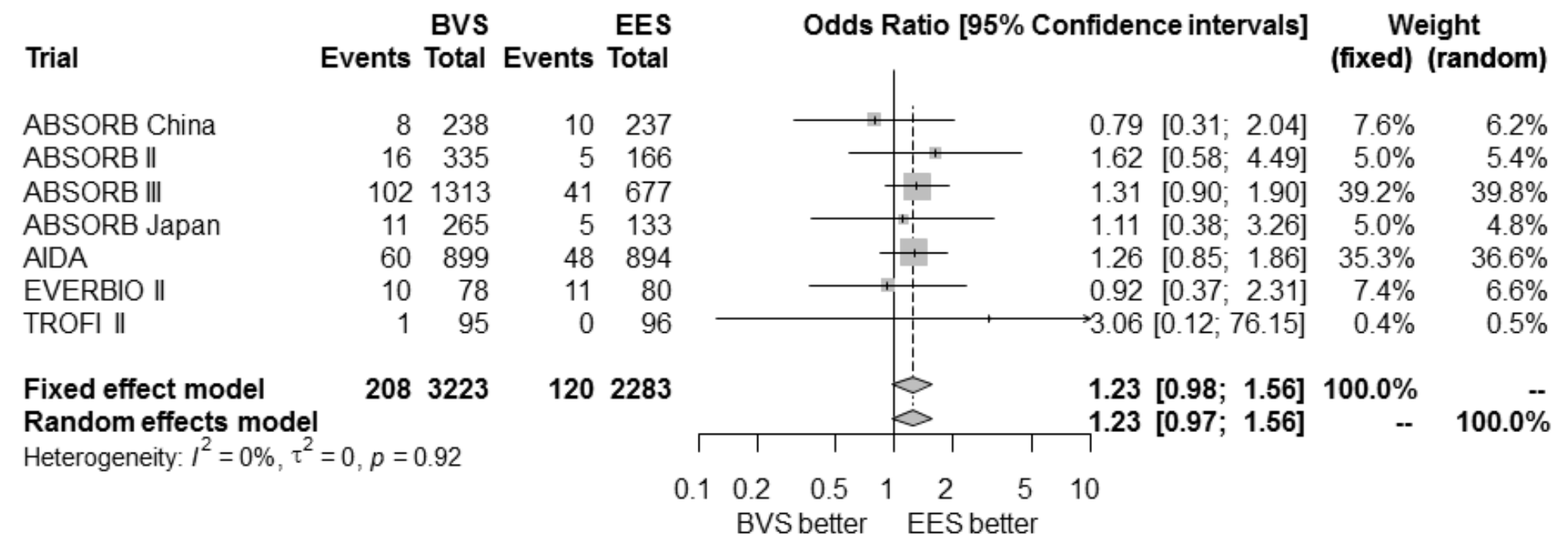

S_Figure 2-A 


\section{Target lesion failure at $\mathbf{2 4}$ months}

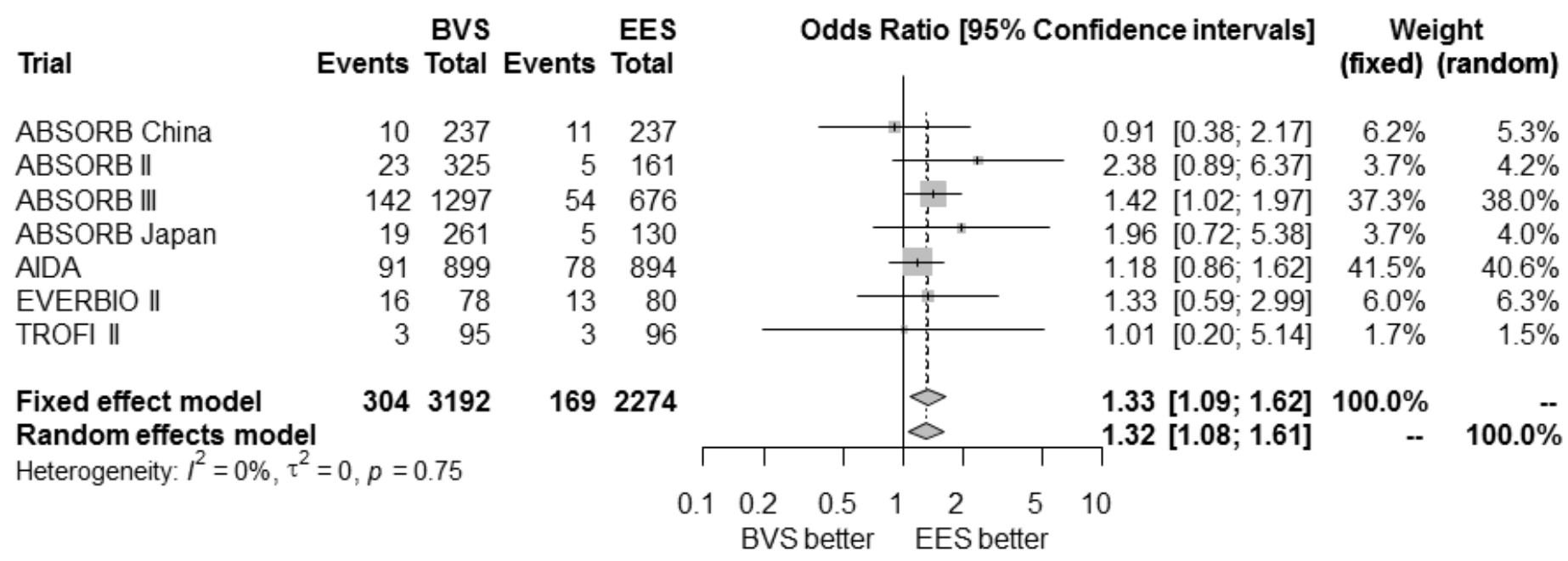

S_Figure 2-B 


\section{Target lesion failure beyond 12 months}

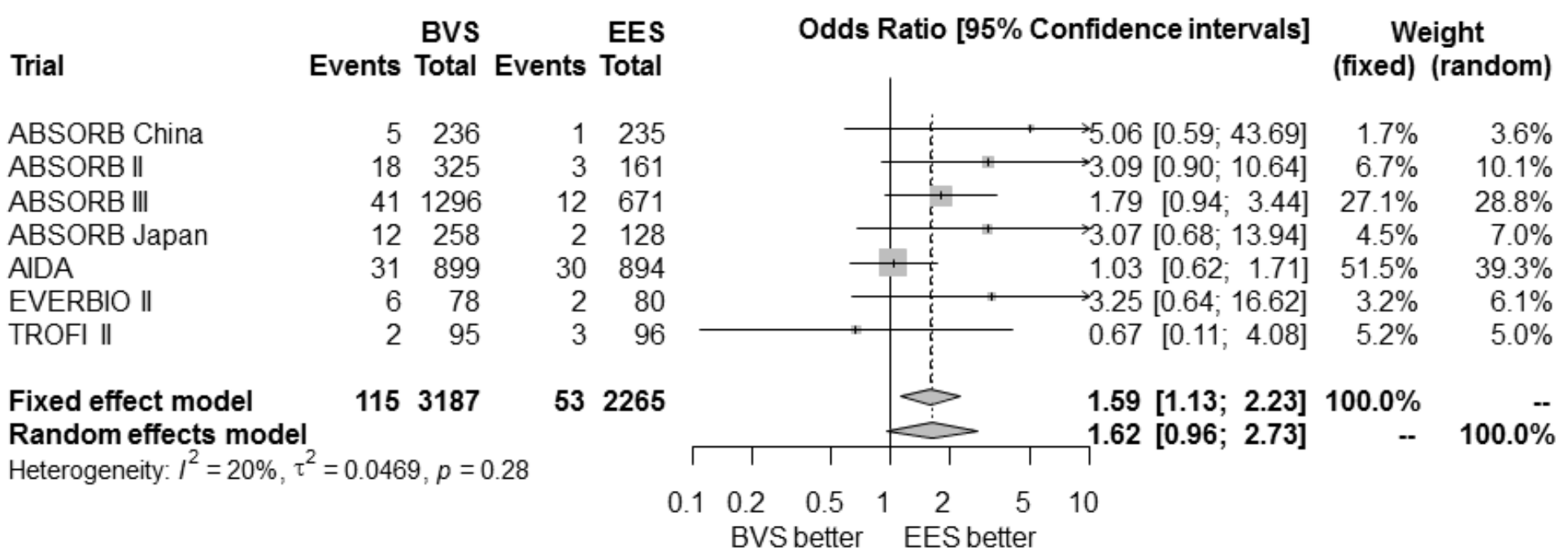




\section{Definite or probable stent/scaffold thrombosis at 12 months}

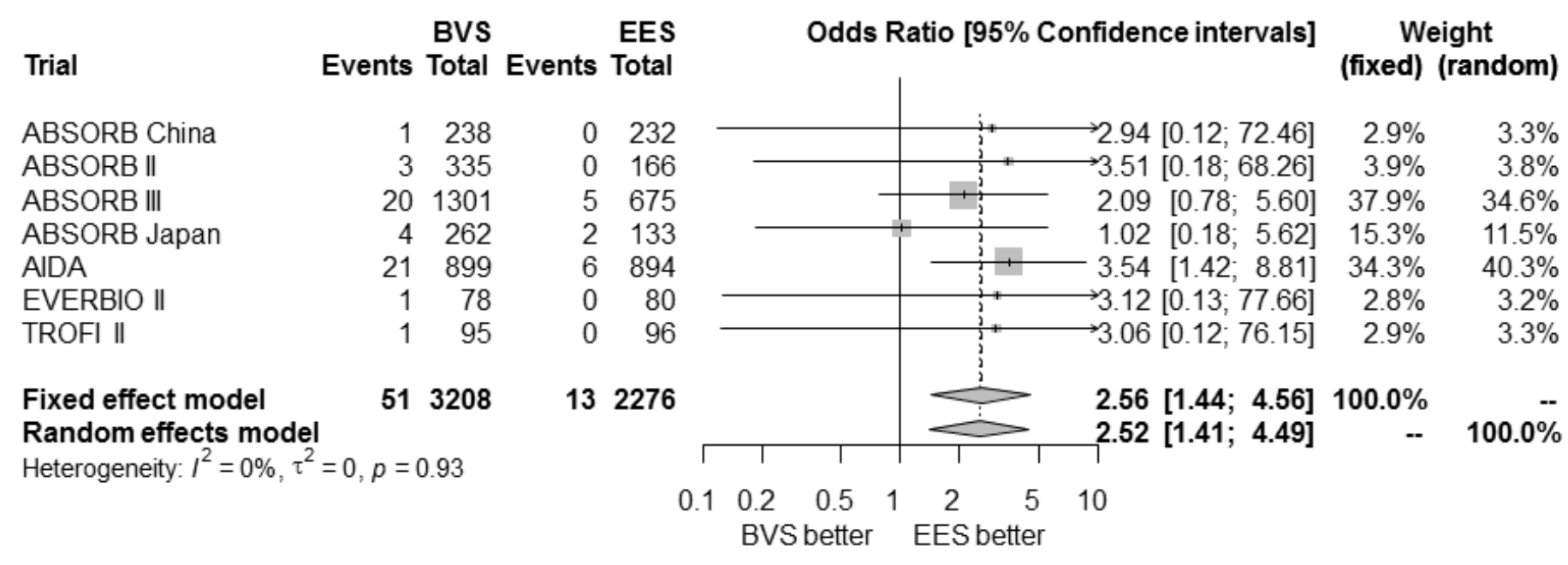

S_Figure 3-A 


\section{Definite or probable stent/scaffold thrombosis at $\mathbf{2 4}$ months}

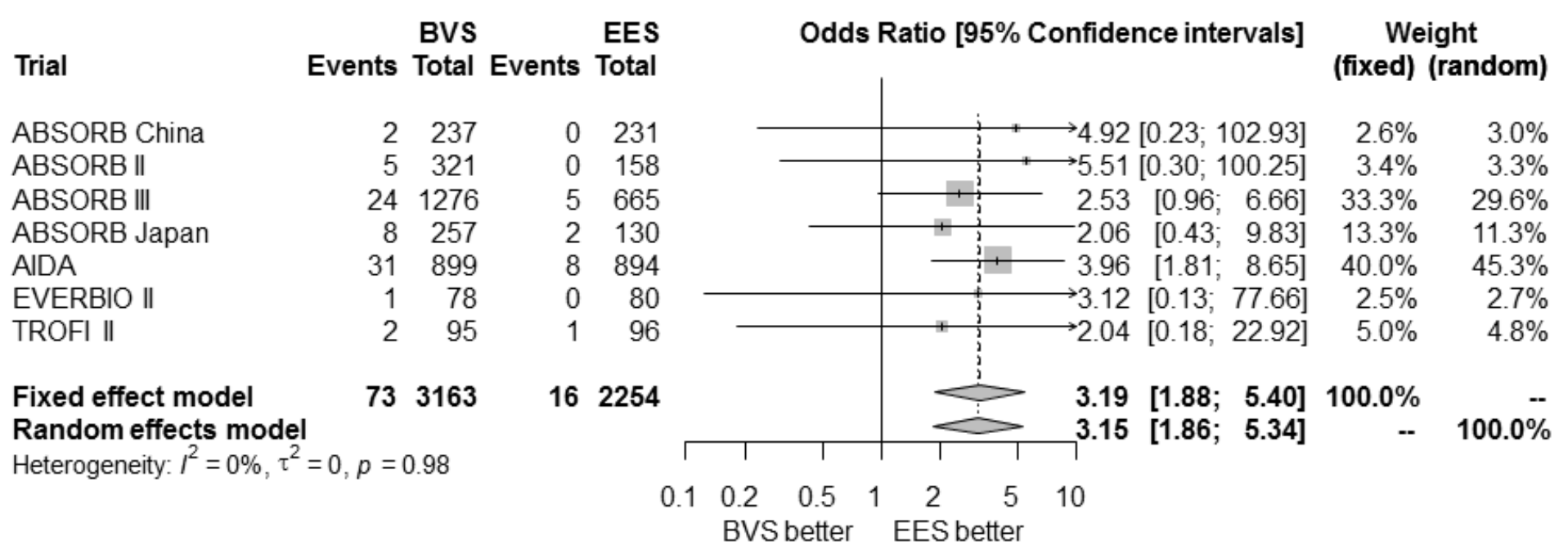

S_Figure 3-B 


\section{Definite or probable stent/scaffold thrombosis beyond 12 months}

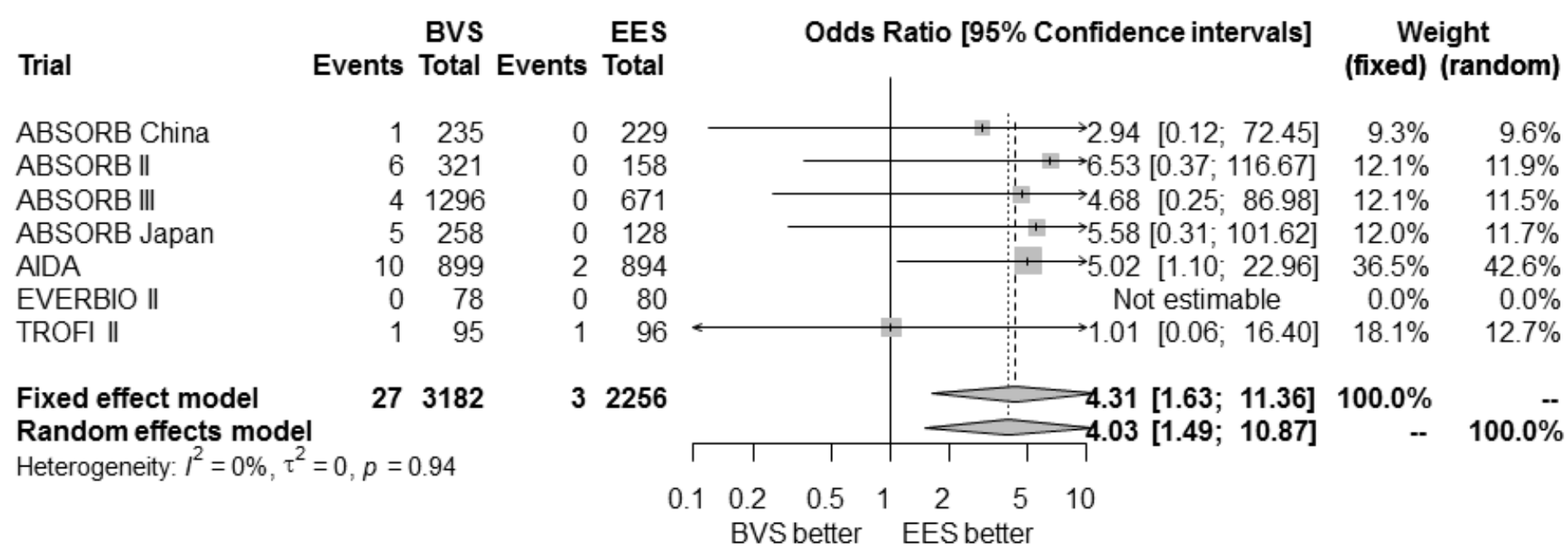




\section{Definite stent/scaffold thrombosis}

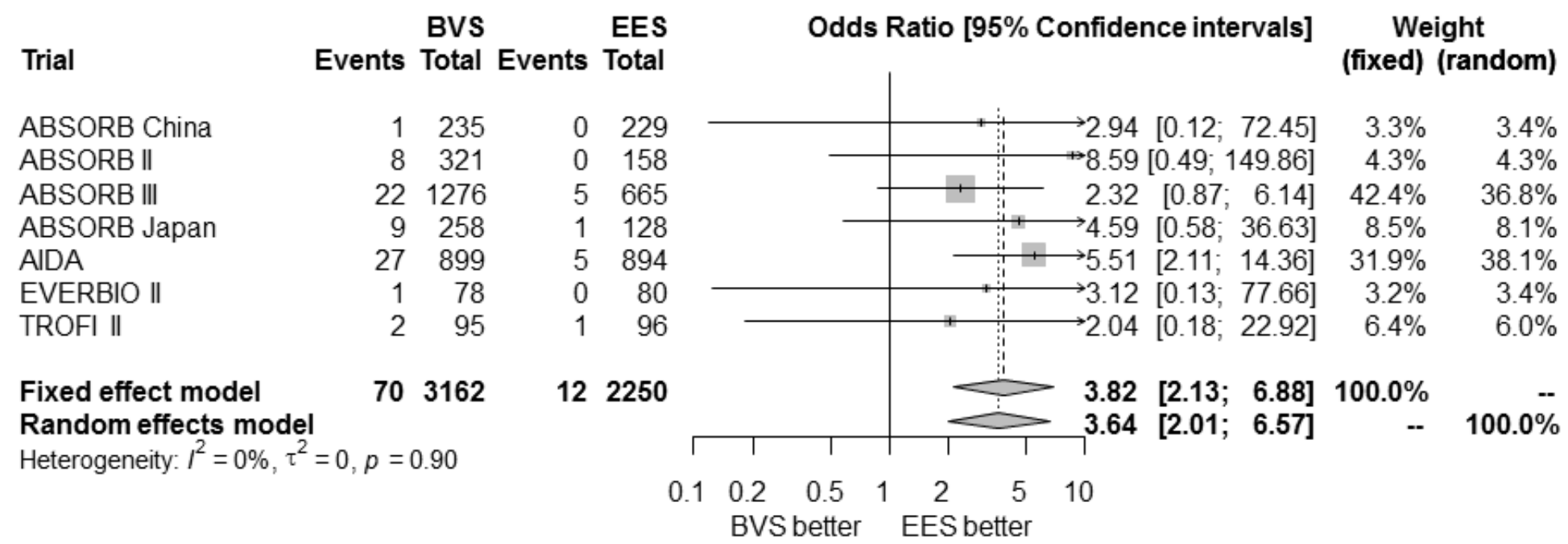




\section{Very late definite stent/scaffold thrombosis}

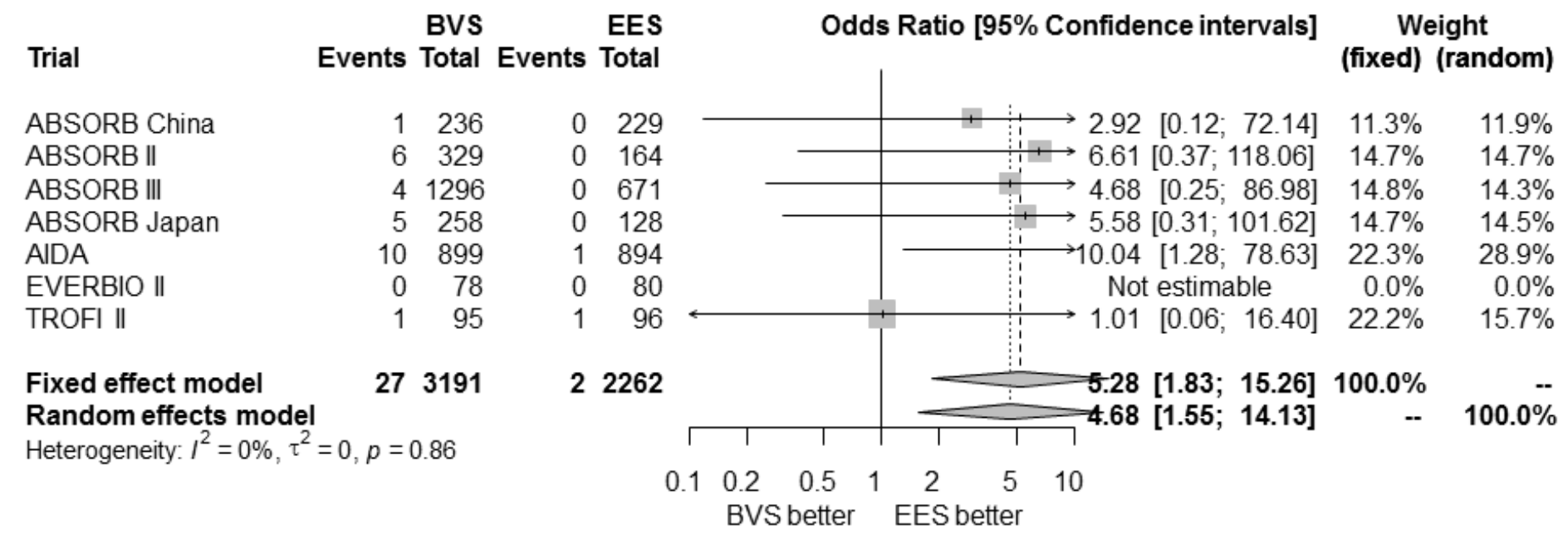

S_Figure 4-B 


\section{Death}

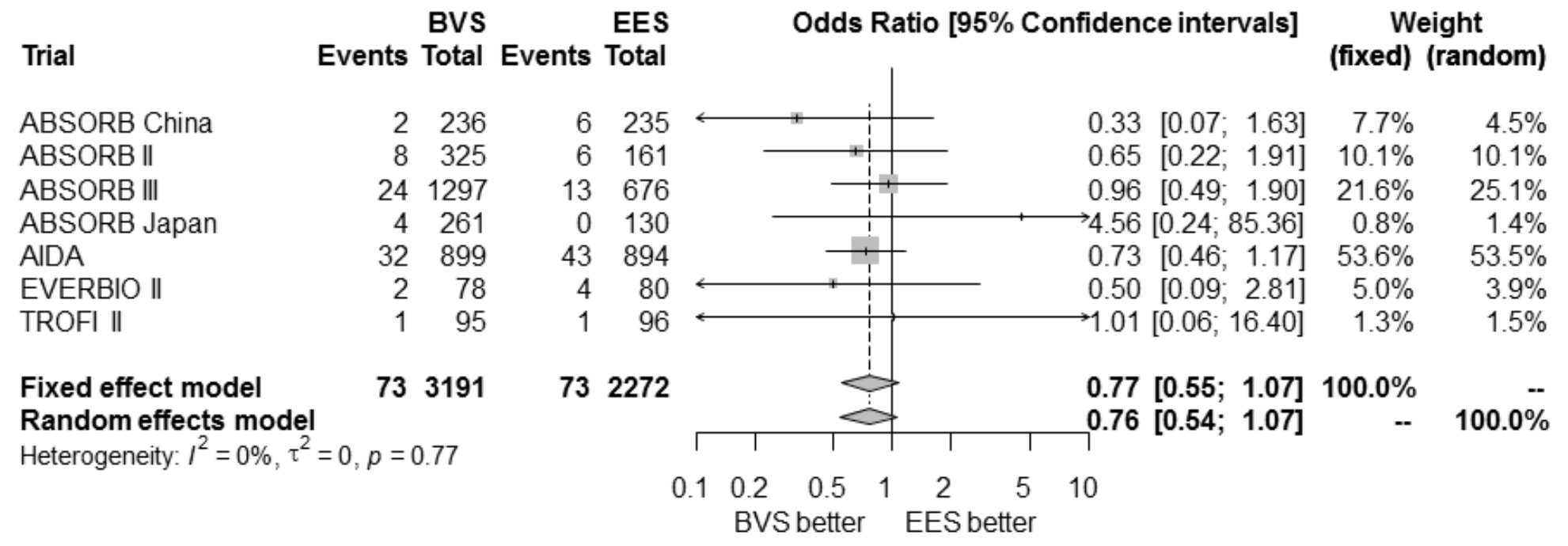




\section{Myocardial infarction}

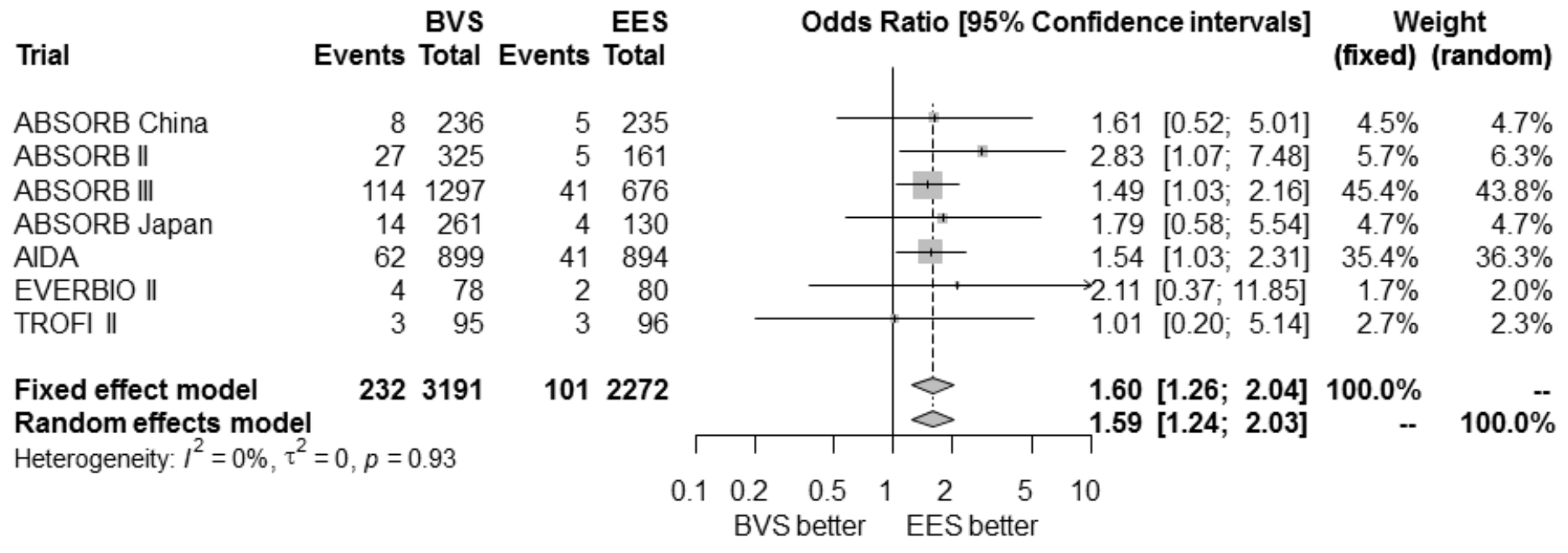

S_Figure 5-B 


\section{Target lesion revascularization}

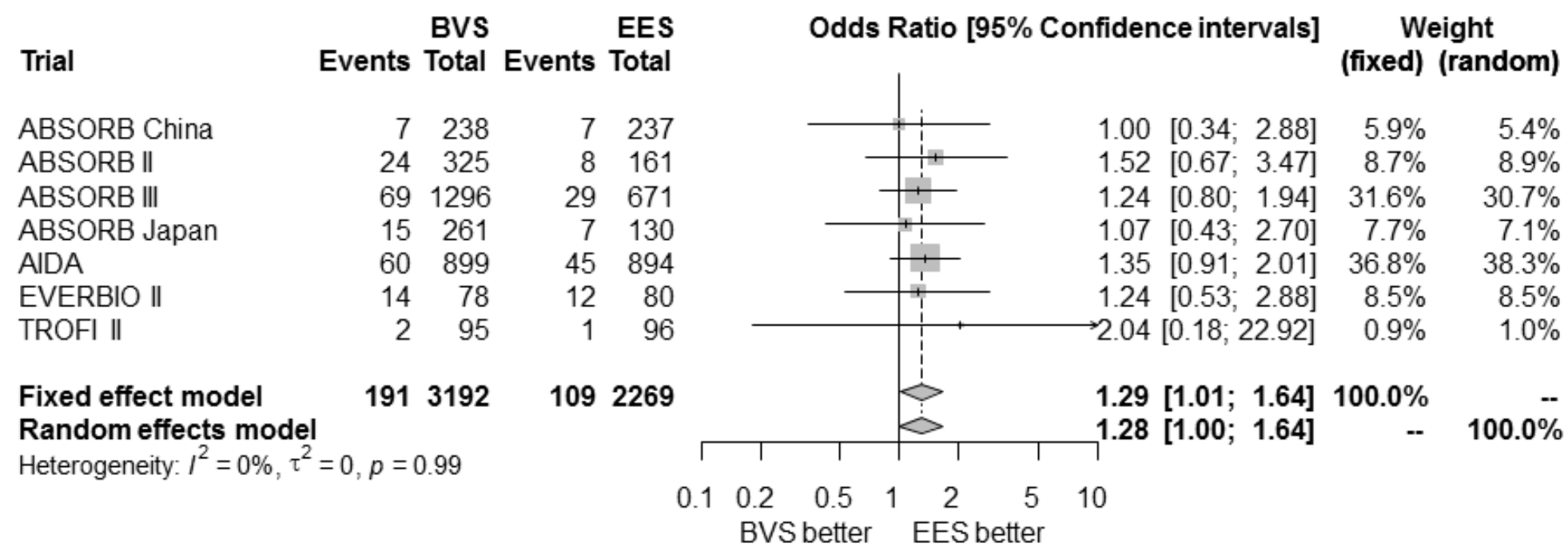

S_Figure 5-C 


\section{Any revascularization}

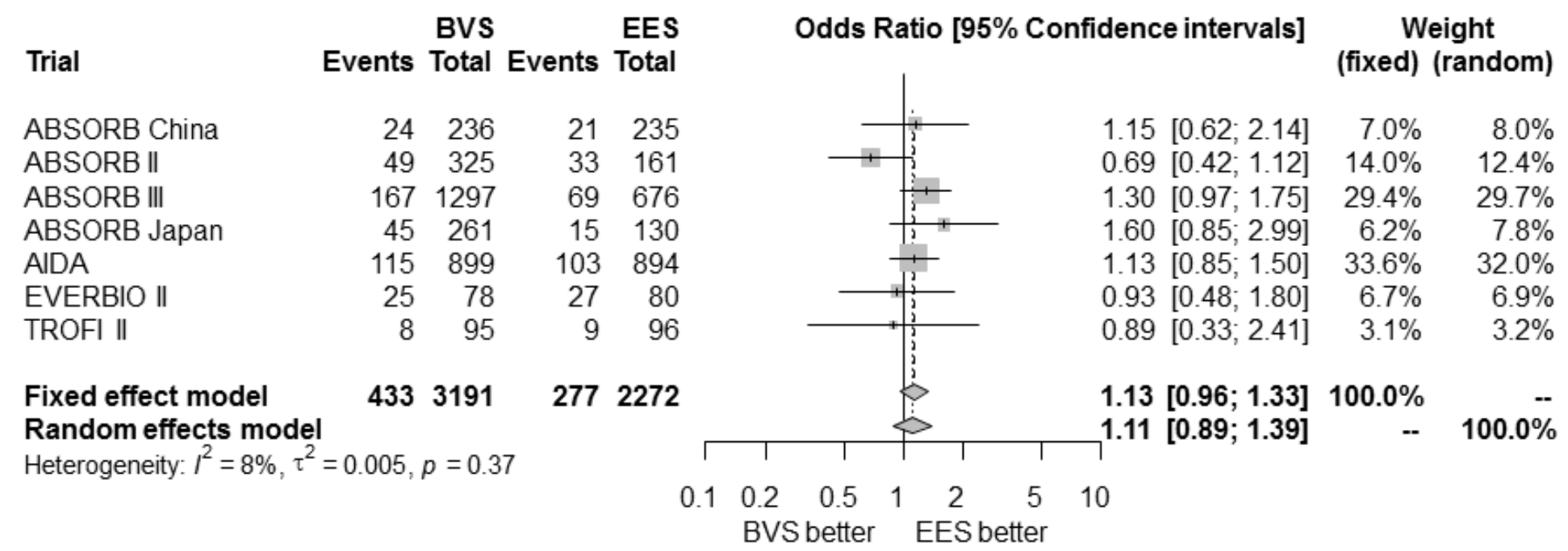

S_Figure 5-D 


\section{Target lesion failure}

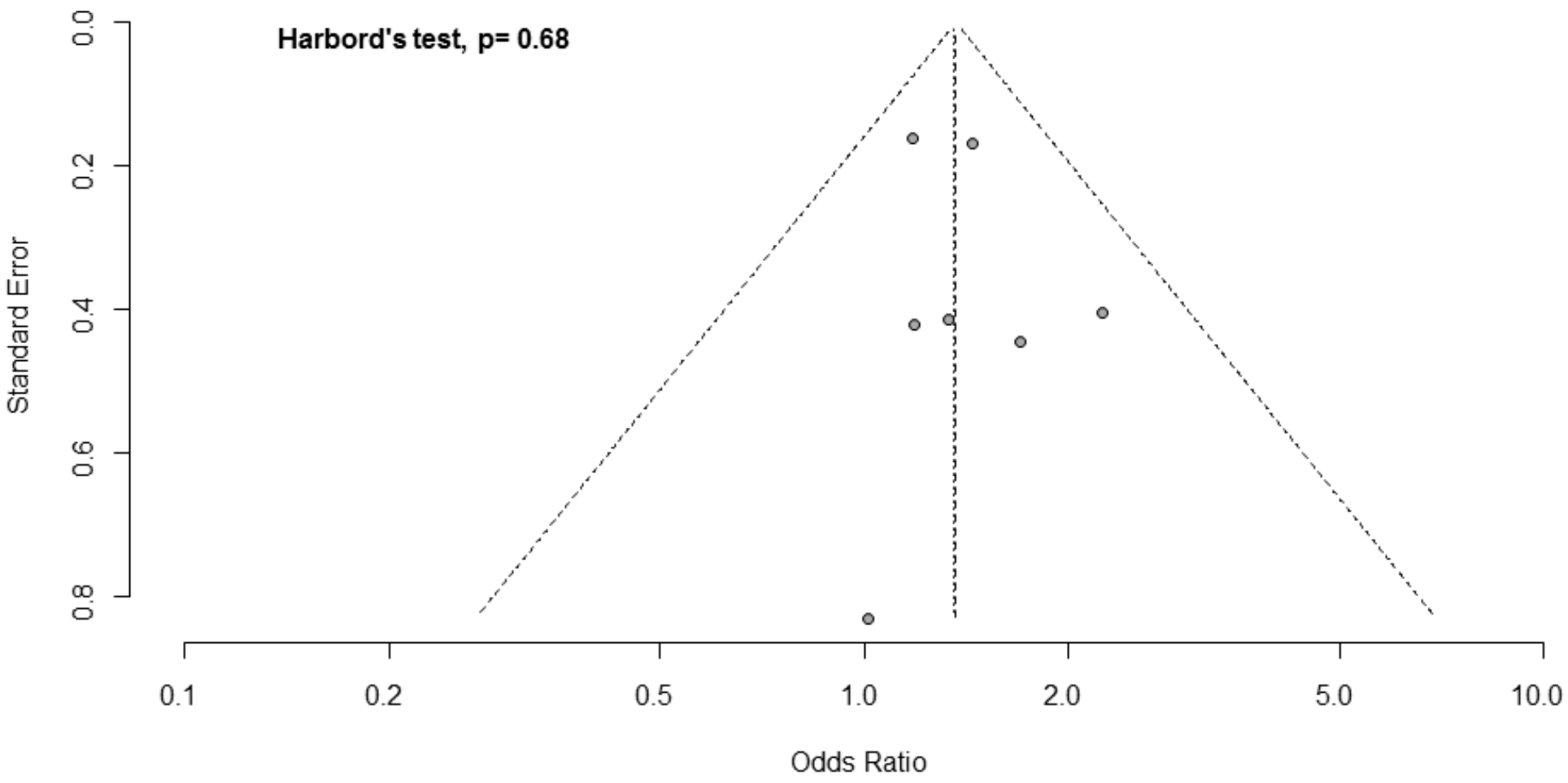

S_Figure 6-A 


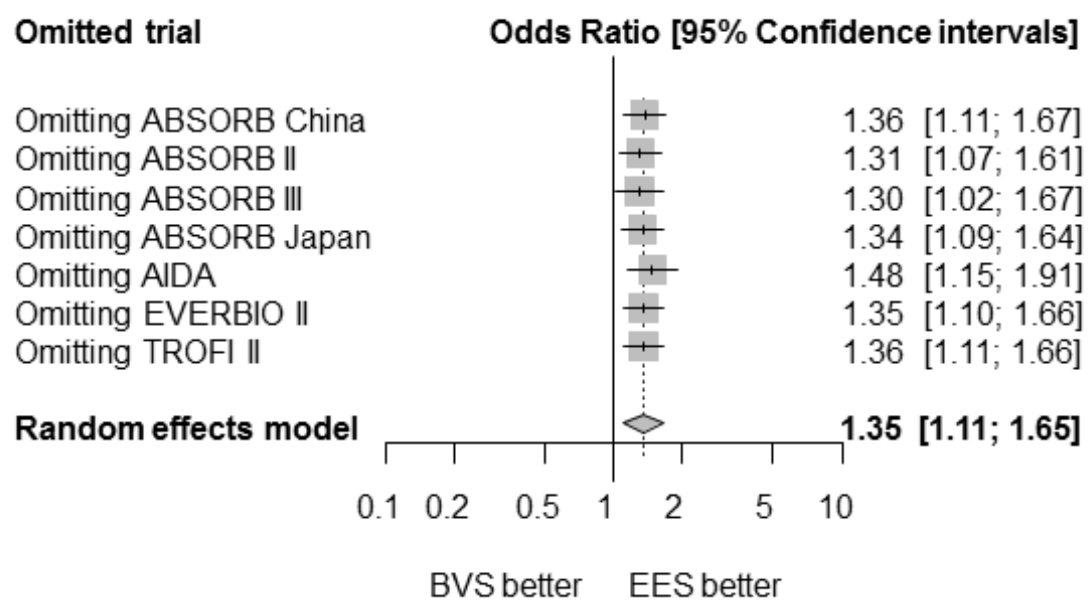

S_Figure 6-B 
Definite or probable stent/scaffold thrombosis

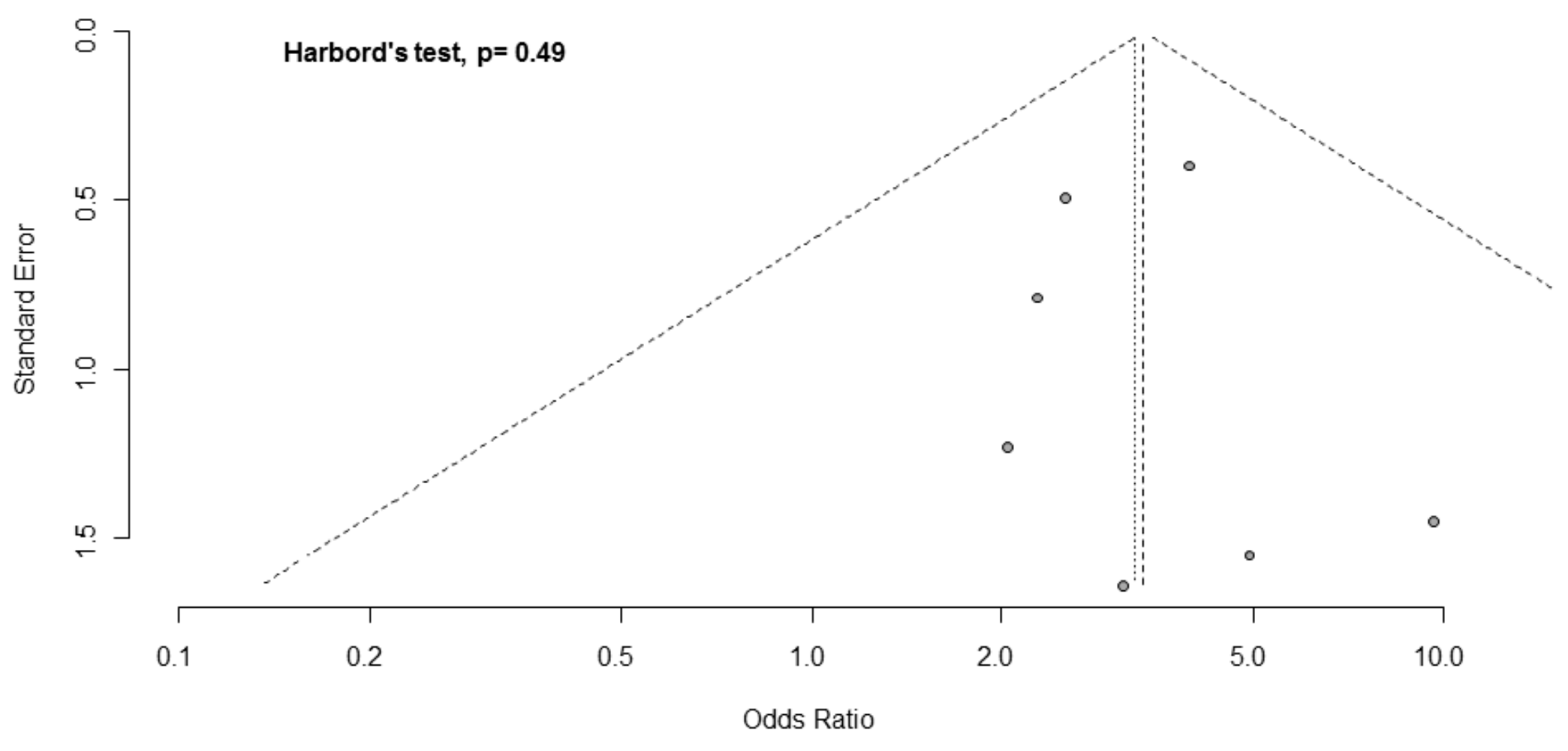

S_Figure 7-A 
Omitted trial

Omitting ABSORB China

Omitting ABSORB ॥

Omitting ABSORB III

Omitting ABSORB Japan

Omitting AIDA

Omitting EVERBIO ॥

Omitting TROFI ॥

Random effects model

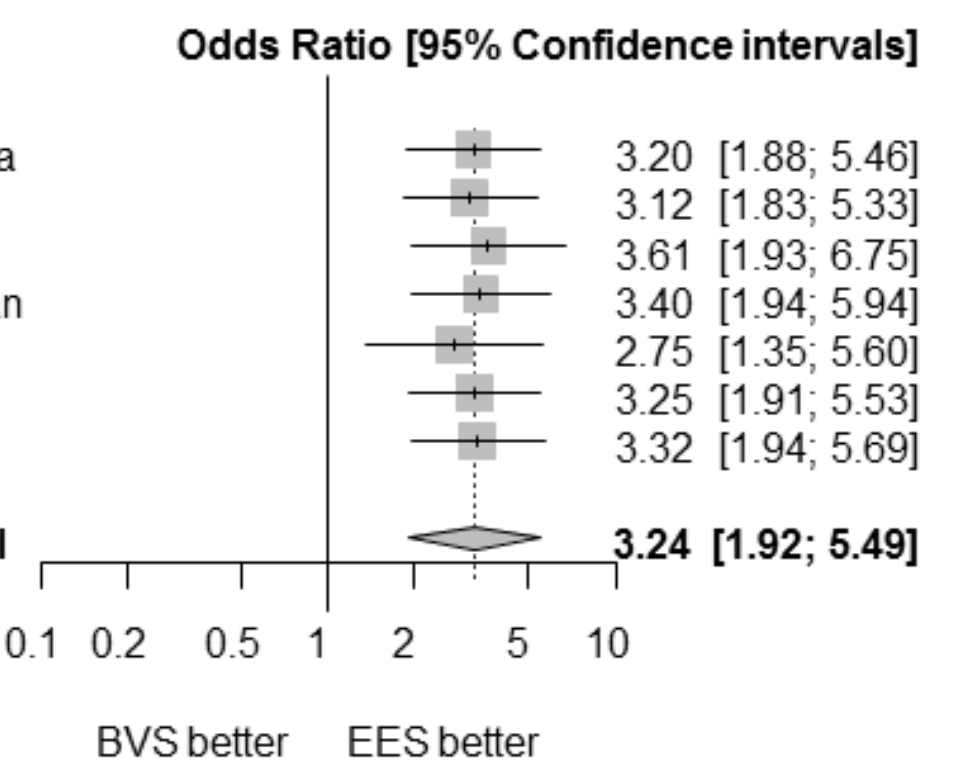

